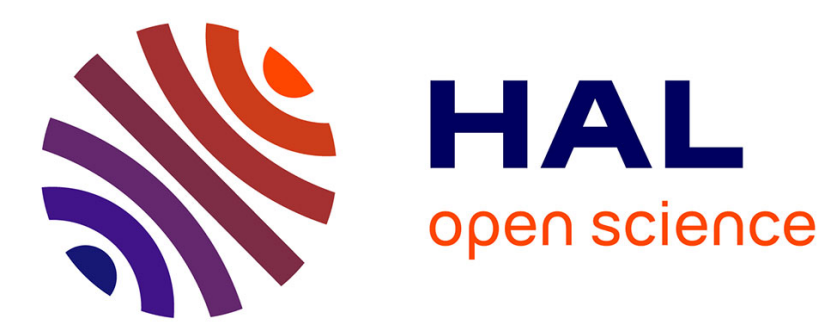

\title{
High-Temperature Behavior of Early Life Membrane Models
}

Loreto Misuraca, Antonino Caliò, Isabelle Grillo, Axelle Grélard, Philippe Marie Oger, Judith Peters, Bruno Demé

\section{> To cite this version:}

Loreto Misuraca, Antonino Caliò, Isabelle Grillo, Axelle Grélard, Philippe Marie Oger, et al.. High-Temperature Behavior of Early Life Membrane Models. Langmuir, 2020, 10.1021/acs.langmuir.0c02258 . hal-02988681

\section{HAL Id: hal-02988681 \\ https://hal.science/hal-02988681}

Submitted on 4 Nov 2020

HAL is a multi-disciplinary open access archive for the deposit and dissemination of scientific research documents, whether they are published or not. The documents may come from teaching and research institutions in France or abroad, or from public or private research centers.
L'archive ouverte pluridisciplinaire $\mathbf{H A L}$, est destinée au dépôt et à la diffusion de documents scientifiques de niveau recherche, publiés ou non, émanant des établissements d'enseignement et de recherche français ou étrangers, des laboratoires publics ou privés. 


\title{
High Temperature Behaviour of Early Life Membrane Models
}

\author{
Loreto Misuraca $^{\mathrm{a}, \mathrm{b}}$, Antonino Caliò ${ }^{\mathrm{b}, \mathrm{c}}$, Isabelle Grillo ${ }^{\mathrm{b}}$, Axelle Grélard ${ }^{\mathrm{d}}$, Philippe \\ Marie Oger ${ }^{\mathrm{c}}$, Judith Peters ${ }^{\mathrm{a}, \mathrm{b}}$, Bruno Demé \\ 5 a Univ. Grenoble Alpes, CNRS, LIPhy, 38000 Grenoble, France \\ ${ }^{\mathrm{b}}$ Institut Laue - Langevin, F-38042 Grenoble Cedex 9, France \\ ' INSA Lyon, Université de Lyon, CNRS, UMR5240, Villeurbanne, France \\ ${ }^{\mathrm{d}}$ Univ. Bordeaux, CNRS, IECB, 33607 Pessac, France
}

10 Abstract: Origin of life scenarios generally assume an onset of cell formation in terrestrial hot springs or in the deep oceans close to hot vents, where energy was available for non-enzymatic reactions. Membranes of the protocells had therefore to withstand extreme conditions different from what is found on Earth's surface today. We present here an exhaustive study of temperature stability up to $80{ }^{\circ} \mathrm{C}$ of vesicles formed by a mixture of short-chain fatty acids and alcohols, which are

15 plausible candidates for membranes permitting the compartmentalization of protocells. We confirm that the presence of alcohol has a strong structuring and stabilizing impact on the lamellar structures. Moreover and most importantly, at high temperature $\left(>60^{\circ} \mathrm{C}\right)$ we observe a conformational transition in the vesicles, which results from vesicular fusion. Because all the most likely environments for the origin of life involve high temperature, our results imply the need to take into account such a transition and its effect when studying a protomembrane model's behaviour.

\section{Introduction}

Compartmentalization of the protocell and thus the formation of the lipid boundary between the cell and its environment is central to the emergence of early life and to assure the required conditions for energy-dependent life processes. Indeed, uni- or multi-lamellar vesicles (ULV - MLV) are believed to

25 be the ancestors of cell membranes ${ }^{1,2}$ and to have provided a privileged environment to early biopolymers, enabling the formation of the earliest protomembranes and cells. To create such barriers, membranes were composed of self-assembling amphiphilic molecules. Contemporary membranes are all based on phospholipids, a group of highly functionalized, diverse and adaptable molecules, whose presence at the early stages of life is not probable. Another aspect that suggests the progressive transition between early amphiphiles and modern phospholipids is that the latter require a complex synthesis pathway and are unlikely to have been produced spontaneously, but rather elaborated in successive selective steps ${ }^{3}$. 
In contrast, simple amphiphilic substrates were likely formed in the relatively harsh but potentially wet conditions of the early Earth by Fischer-Tropsch processes ${ }^{4,5}$. Photo-oxidation likely valorized

35 alkanes by transforming them into oxygenated amphiphilic material such as fatty acids and fatty alcohols. This synthesis would have led to high abundance of short chain Fatty Acids (FA) $(\mathrm{C}<12)$, the abundance of which fall exponentially with the tail length ${ }^{1,6}$. FA have been proven to form vesicles when the chain length is eight or more carbons ${ }^{7}$.

Pioneering work has documented the ability of these amphiphiles to form membrane structures in

40 solution, the stability of which is strongly dependent on environmental conditions ${ }^{8}$. The first requirement for vesicle formation is a solution $\mathrm{pH}$ equivalent to the $\mathrm{FA}$ dissociation constant $\left(\mathrm{pK}_{\mathrm{a}}\right)$, so that approximately half of the protonated molecules act as hydrogen bond donor to the adjacent ionized ones ${ }^{9,10}$. The second requirement is to reach the Critical Vesicle Concentration (CVC) ${ }^{9}$, below which these single chain amphiphiles exist only as monomers in solution or aggregated in 45 micellar structures. The CVC of pure FA vesicles has been measured quantitatively as a function of the chain length ${ }^{7}$. A decrease in the CVC was observed with increasing chain length, as expected, because longer apolar hydrocarbon tails favour the more packed bilayered structures. Furthermore, the addition of small amounts of fatty alcohols (with same length as the FA, in a 10:1 FA : alcohol molar ratio) was found to dramatically lower the $\mathrm{CVC}$ and also to allow vesicle formation at $\mathrm{pH}$ values

50 higher than the $\mathrm{pK}_{\mathrm{a}}$ of the acid. This can be explained because the alcohol ability to form hydrogen bonds with the anionic FA balances the lack, at high $\mathrm{pH}$, of hydrogenated FA that would serve the same purpose (as it happens in the pure FA samples around its $\mathrm{pK}_{\mathrm{a}}$ ). However, FA vesicles do not withstand high salinity, especially when divalent cations such as $\mathrm{Mg}^{2+}$ or $\mathrm{Ca}^{2+}$ are involved ${ }^{7,11,12}$.

All these major limitations have led to a paradoxical situation where the molecules able to self55 assemble into vesicles that were probably the most abundant in an origin of life scenario, namely the FA with $\mathrm{C}<12$, are also seen as the least promising ones because of their observed sensitivity to the environment.

Some of these apparent issues have been potentially solved by considering a mixture of the same chain alcohol and FA, as mentioned above, for its effect on the CVC and the $\mathrm{pH}$ of vesicle formation.

60 On the other hand, the sensitivity towards salt concentration has also been shown to be lowered either by alcohol addition ${ }^{13}$, by using mixtures of different length FA ${ }^{14}$ or by prebiotic amino acids binding the FA membrane ${ }^{15}$. These studies prove that ways to overcome the sensitivity towards high salinity exist while still considering plausible prebiotic systems and environmental conditions. Yet, previous studies on the thermal behaviour and stability of protomembranes have been focusing on longer 65 aliphatic chains ${ }^{16,17}$ driven by the observed environmental sensitivity at ambient temperature. Nevertheless, some surprisingly thermostable properties have been observed even for vesicles made with short chain amphiphiles. In particular, vesicles made with mixtures of decanoic "capric" acid - 
decanol or "capric" acid - decanol - monocaprin (2:1 and 4:1:1 molar ratio, respectively) where shown to retain encapsulated oligonucleotides up to $70{ }^{\circ} \mathrm{C}$ for more than $1 \mathrm{~h}$, or $100{ }^{\circ} \mathrm{C}$ for more than $701 \mathrm{~min}{ }^{16}$. These findings suggest that the observed sensitivity of the membranes made by short aliphatic chains towards changes in $\mathrm{pH}$, amphiphile and salt concentrations, do not necessarily imply a lack of stability towards temperature variations.

A first temperature-pressure study of the C10 mixture (capric acid+decanol 1:1 ratio) in buffered solution (bicine $0.2 \mathrm{M} \mathrm{pH} 8.5$ ) has been performed by Kapoor et al. ${ }^{18}$. They observed and assigned 75 two phase transitions experienced by the system: the first, at $10{ }^{\circ} \mathrm{C}$, identified as "the appearance of disordered fluid-like chains"; the second, at $\approx 60{ }^{\circ} \mathrm{C}$, explained as "morphological changes of lipid entities with overall fluid-like chains" (e.g. a shift in the micelle-vesicle equilibrium). Interestingly, they also observed an increase of the vesicle size beyond $50{ }^{\circ} \mathrm{C}$ (diameter increasing from $120 \mathrm{~nm}$ at $45^{\circ} \mathrm{C}$ to $160 \mathrm{~nm}$ at $\left.55^{\circ} \mathrm{C}\right)$, although the temperature range investigated $\left(5-55^{\circ} \mathrm{C}\right)$ did not allow them to study in more detail the phenomenon at higher temperatures.

In this article, we extend the studies up to $80{ }^{\circ} \mathrm{C}$ and present a deeper and quantitative characterization of the membrane model composed of a capric acid:decanol 1:1 mixture (hereafter called C10 mix, Figure 1a) by following the properties and the evolution of the corresponding vesicles (partitioning, size distribution, lamellarity, membrane thickness, signs of micelle presence), as a promising model 85 of protocellular compartmentalization. We compare its characteristics with a similar model made of pure capric acid (Figure 1b). The stability with temperature is investigated for both systems, to understand the capability of the vesicles to withstand the high temperatures expected at hydrothermal vents/hot springs. It is of great interest to investigate the thermal stability of the protomembranes, as the high temperature would have allowed a number of important non-enzymatic reactions to take place (e.g. DNA strand separation and reannealing) ${ }^{16}$.

We find that the alcohol insertion leads to a number of substantial differences in the vesicle behaviour:

1) It leads to a much larger proportion of vesicles, at the expense of other aggregates (micelles) or monomers in solution;

2) It protects vesicles from low temperature vesicle disruption, maintaining the multilamellar structures when present;

3) It triggers an abrupt conformational change above $60^{\circ} \mathrm{C}$. This leads to a transition from multilamellar vesicles to large unilamellar structures.

Such findings, in turn, could set a high T limit for the stability of vesicle systems to $60{ }^{\circ} \mathrm{C}$ at ambient pressure, but could also open new alternative perspectives related to the observed changes in the 
amphiphiles self-assembly. Our results point towards an alcohol induced, $\mathrm{T}$ triggered and slowly reversible vesicular fusion process.

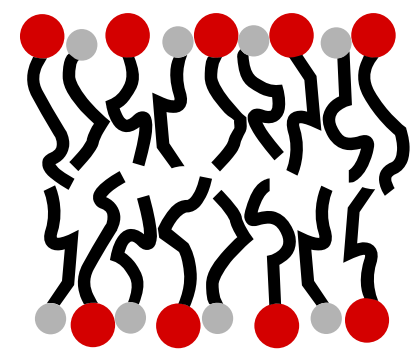

(a)

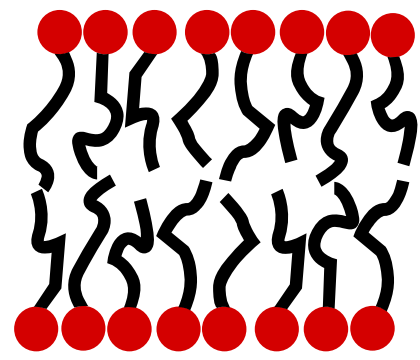

(b)

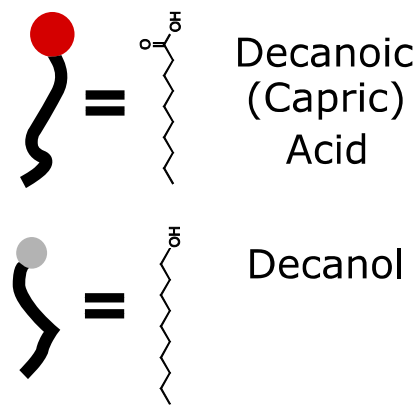

Figure 1. The protomembrane models: (a) Bilayer made from a mixture of capric acid and decanol; (b) bilayer made of capric acid.

\section{Experimental}

\section{$\underline{\text { Sample preparation }}$}

Decanoic acid, 1-decanol, bicine buffer and $\mathrm{D}_{2} \mathrm{O}$ were purchased from Sigma Aldrich (Merck). The samples were prepared by dissolving the Decanoic acid (and the decanol, when needed) in a $\mathrm{CHCl}_{3}$ solution, followed by drying with a flush of nitrogen (the Decanoic acid + 1-decanol mixture is liquid at ambient temperature). The samples were then placed in a dessicator and left under vacuum overnight. The sample weights were checked at each step, to make sure that all the chloroform was evaporated. At the final stage, a sample loss of $\approx 5 \%$ was measured for the $\mathrm{C} 10$ mix samples, probably due to a partial evaporation of the decanol. The final Decanoic acid : 1-decanol in the C10 mix samples was 1:1.

The bicine buffer was prepared at a concentration of $0.2 \mathrm{M}$ in $\mathrm{H}_{2} \mathrm{O}$. For the NMR experiments, the buffer was solubilized in ${ }^{2} \mathrm{H}$ depleted water. In the case of SANS experiments, the buffer solution was prepared by dissolving hydrogenated bicine in $\mathrm{D}_{2} \mathrm{O}$. In all cases, the buffer was filtered with a $0.2 \mu \mathrm{m}$ millipore membrane before use.

120 The dried organic solutions were then suspended in buffer, titrated to desired $\mathrm{pH} / \mathrm{pD}$ with aliquots of $\mathrm{NaOH} / \mathrm{NaOD}$, and vigorously vortexed, leading to final milky-foamy solutions.

For the Solid State NMR and SANS on D16 experiments, the total amphiphile concentration was set to $350 \mathrm{mM}$ and the samples were measured as they were at this stage.

For DSC, SLS-DLS and SANS on D33, the total amphiphile concentration was $80 \mathrm{mM}$. Samples were

125 extruded using the equipment provided by Avanti Polar Lipids, with the heating block regulated at 40 ${ }^{\circ} \mathrm{C}$ and using $100 \mathrm{~nm}$ polycarbonate membranes. The extrusion was always performed with 11 passes 
per sample and less than $24 \mathrm{~h}$ before the corresponding experiments. Light Scattering precharacterization measurement ensured that the extruded vesicles were stable at ambient temperature for several days (data not shown).

\section{Static - Dynamic Light Scattering}

The multi-angle Static Light Scattering Measurements in the angular range 25-150 and the Dynamic Light scattering measurements at $150^{\circ}$ (giving the results of Figure 2 in the text) were performed on an ALV CGS-3 instrument (ALV GmbH, Langen, Germany) at the Institut Laue Langevin (ILL) Grenoble with an incoming laser light of $\lambda=633 \mathrm{~nm}$ wavelength. $1 \mathrm{ml}$ of each sample was loaded on round bottom borosilicate cuvettes after filtration through $0.45 \mu \mathrm{m}$ Millipore filters $(0.2 \mu \mathrm{m}$ for the buffer), and left $10 \mathrm{~min}$ in the toluene bath for thermalisation before starting the measurements. A buffer measurement at the same conditions was performed to subtract its contribution, as well as toluene as a standard with known Rayleigh ratio $\left(R_{\mathrm{tol}}=1.35^{*} 10^{-5} \mathrm{~cm}^{-1}\right)$ :

$$
\mathrm{R}_{\text {sample }}=R_{\text {tol }} *\left(\mathrm{I}_{\text {sample }}-\mathrm{I}_{\text {solvent }}\right) / \mathrm{I}_{\text {toluene }}
$$

140 where $R$, the Rayleigh ratio, is defined as the scattered intensity per unit of solid angle, scattering volume and incident intensity; I is the scattered intensity. The scattered intensity is corrected for the scattering volume (the sample volume visible for the detector) using $I_{\text {sample/solv/tol }}=I_{\exp } * \sin (\theta) / I_{0}$, where $\theta$ is the scattering angle and $\mathrm{I}_{0}$ the incoming intensity.

For the DLS measurements at $90^{\circ}$ fixed angle, as a function of temperature, the instrument used was a

145 Malvern Zetasizer Nano ZS90. For the latter, $200 \mu 1$ quartz cells were used.

For the SLS measurements (ALV), the scattered intensity was collected for $10 \mathrm{~s}$ per angle. For DLS (ALV and Malvern), 3 runs of $30 \mathrm{~s}$ each were collected per angle for an error estimation of the diffusion coefficients.

The SLS scattering data were treated using the Guinier approximation ${ }^{19}$, whose validity was verified

150 for the $100 \mathrm{~nm}$ extruded vesicles. In fact, for the cases where $\mathrm{q}^{*} \mathrm{R}_{\mathrm{g}} \leq 1$ ( $\mathrm{q}$ being the scattering vector, $\mathrm{q}$ $=4 \pi \mathrm{n} \sin (\theta / 2) ; \mathrm{R}_{\mathrm{g}}$ the gyration radius), one can approximate the scattering intensity (the Rayleigh ratio) as:

$$
\ln R_{\text {sample }} \approx \ln \left(\mathrm{I}_{0}\right)-\mathrm{q}^{2} \mathrm{R}_{\mathrm{g}}{ }^{2} / 3
$$

so that in a log-linear plot, the slope of the fitted line gives an estimation of $\mathrm{R}_{\mathrm{g}}$.

155 The Dynamic Light Scattering correlation functions were analysed following the method of the moments (a re-visitation of the method of cumulants) developed in ${ }^{20}$. The first two moments $\mu_{1}$ (corresponding to the decay rate $\Gamma$ ) and $\mu_{2}$ were left as free parameters in the fit. For particles moving by Brownian diffusion, the decay rate is linked to the diffusion coefficient $\mathrm{D}$ by the relation $\Gamma=\mathrm{D} \mathrm{q}^{2}$. 
In some cases, a sum of two populations, each one having its own $\mu_{1}$ and $\mu_{2}$, was necessary for successful fits (indicating the existence of different families of scatterers of different sizes).

The Brownian diffusion coefficients D experimentally determined where then used to estimate the hydrodynamic radius $\mathrm{R}_{\mathrm{h}}$ using the Stokes-Einstein equation:

$$
\mathrm{D}=\mathrm{k}_{\mathrm{B}} \mathrm{T} /\left(6 \pi \mathrm{R}_{\mathrm{h}} \mu\right)
$$

with $\mathrm{D}$ the diffusion coefficient, $\mathrm{k}_{\mathrm{B}}$ the Boltzmann constant, $\mathrm{T}$ the temperature, $\mu$ the solvent viscosity

165 (solvent viscosity and refraction index $n$ were assumed the same as for $\mathrm{H}_{2} \mathrm{O}$ ).

Fits of the DLS autocorrelation functions were performed using the Origin software (OriginLab Corp., Northampton, MA).

\section{Differential Scanning Calorimetry}

For the DSC experiments, a microDSCIII calorimeter (Setaram, France) was used. Two Hastelloy C

170 cells of $0.5 \mathrm{ml}$ sample volume were used for both the samples and the buffer. The samples were measured against the buffer as a reference. The explored temperature range was $-4<\mathrm{T}<85^{\circ} \mathrm{C}$, with scanning rate $0.5^{\circ} \mathrm{C} / \mathrm{min}$. Three heating cycles were collected (the first for annealing, the last two to verify the reproducibility). No corrections or baseline subtractions were applied, the scans being used for qualitative comparison.

\section{Solid State NMR}

The Capric acid sample was prepared by hydrating $6 \mathrm{mg}$ of perdeuterated $\left({ }^{2} \mathrm{H}_{19}\right)$ Capric acid with $100 \mu \mathrm{l}$ of $0.2 \mathrm{M}$ bicine buffer prepared in deuterium-depleted water (hydration of $94 \%$ ). The C10 mix sample was prepared by mixing $3 \mathrm{mg}$ of perdeuterated Capric acid with decanol (1:1 molar ratio) and hydrated with $100 \mu 1$ of the same buffer (hydration of 97\%). Samples were transferred into $100 \mu 14-$ $180 \mathrm{~mm}$ zirconia rotors for NMR analyses. ${ }^{2} \mathrm{H}$-ssNMR experiments were performed at $76.77 \mathrm{MHz}$ with a phase-cycled quadrupolar echo pulse sequence $\left(90^{\circ} \mathrm{x}-\mathrm{t}-90^{\circ} \mathrm{y}\right.$-t-acq) ${ }^{21}$ and using a Bruker Avance III $500 \mathrm{MHz}$ WB $(11.75 \mathrm{~T})$ spectrometer equipped with a solid state CPMAS 4mm H/X probe (IECB structural biophysics platform, Bordeaux, France). Acquisition parameters were as follows: spectral window of $500 \mathrm{kHz}, \pi / 2$ pulse width of $3.9 \mu \mathrm{s}$, interpulse delays of $40 \mu \mathrm{s}$, recycling delay of $1.3 \mathrm{~s}$;

185 number of scans from 500 to 3000. Samples were equilibrated for $30 \mathrm{~min}$ at each temperature before the acquisition. The acquisition time for Capric acid and C10 mix spectra was 10 and 65 min, respectively. Spectra were processed using a Lorentzian line broadening of $400 \mathrm{~Hz}$ before Fourier transformation from the top of the echo. Samples were equilibrated for $30 \mathrm{~min}$ at a given temperature before data acquisition. All spectra were processed and analyzed using Bruker Topspin 4.0.6 software. 
SANS measurements were performed on two instruments, available at the ILL (Grenoble, France):

- D33 [https://www.ill.eu/users/instruments/instruments-list/d33/] ${ }^{22}$, with two neutron wavelength configurations $(\lambda=5 \AA$ and $\lambda=14.5 \AA)$ and three sample-detector distances (2, 10 and $12 \mathrm{~m})$ to cover the widest range of scattering vector $\left(1.3 * 10^{-2}<\mathrm{q}<5.6\right) \mathrm{nm}^{-1}$;

- D16 [https://www.ill.eu/users/instruments/instruments-list/d16/], with neutron wavelength $\lambda=$ $4.5 \AA$ and sample-detector distance $0.95 \mathrm{~m}$, leading to the scattering vector range $\left(2.6 * 10^{-1}<\right.$ $\mathrm{q}<5.3) \mathrm{nm}^{-1}$.

The sample suspensions, of $200 \mu \mathrm{l}$ each, were loaded in $1 \mathrm{~mm}$ quartz cells (Hellma, Germany) on a sample holder with thermal regulation. For the start at low temperature during the temperature scans, samples were equilibrated for at least 20 mins. Then, for every $\mathrm{T}$ jump, the minimum equilibration time before starting the data acquisition of the first sample in the sample changer was $10 \mathrm{~min}$; this time increased as samples were sequentially measured. We did not notice any inconsistencies due to the sample positions in the sample changer. All data were corrected for the scattering of the sample holder and the instrumental background. $\mathrm{H}_{2} \mathrm{O}$ was measured for detector efficiency calculation and

205 scaling to absolute units $\left(\mathrm{cm}^{-1}\right)$. A flat background was subtracted to account for the q-independent incoherent neutron scattering signal.

The outcome from a SANS experiment is a series of curves of I vs. q, where

$$
I(q)=\left|F(q)^{2} * S(q)\right|=|P(q) * S(q)|
$$

$P(q)=F(q)^{2}$ being the particle form factor and $S(q)$ the structure factor. The form factor contains

210 information about the shape of the scatterers at the different length scales (the q range) covered: in the case of vesicles this will be the vesicle size, shape, size polydispersity, lamellarity, bilayer thickness and corresponding polydispersity. The structure factor contains information about possible interaction between neighbour vesicles and, most importantly, the interaction between subsequent membranes forming the MLVs. The position of the first maximum of the correlation, due to the membrane $S(q)$ in 215 a SANS curve, can give a direct estimation of the membrane $d$-spacing through the relation $d=2 \pi / q$ (with d: d-spacing; q: scattering vector).

The fitting of the SANS curves were performed using the SASView public software (http://www.sasview.org/). The equations for all the model form factors employed can be found in the "Material and methods" section (Supp. Info). 

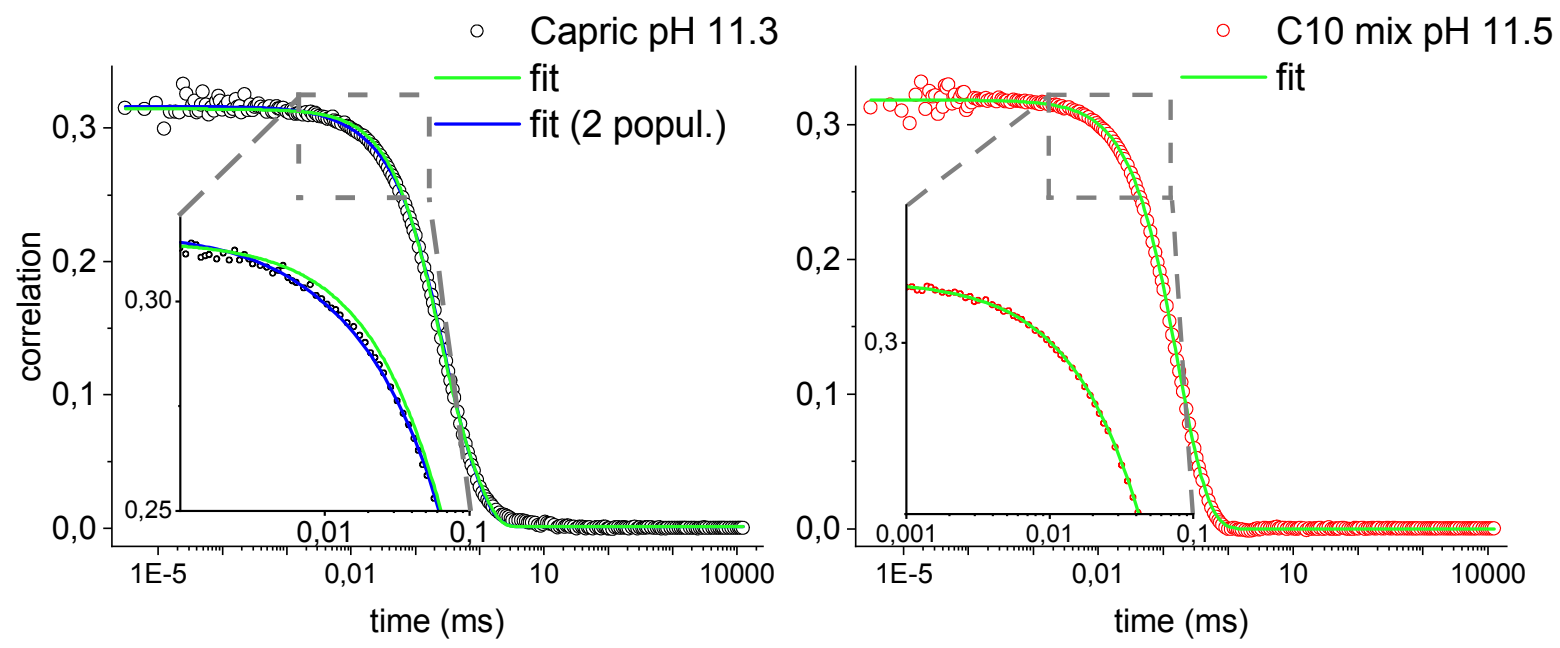

Figure 2. Dynamic light scattering auto-correlation curves at high $\mathrm{pH} 11.4$, and corresponding zooms on the short correlation times (insets) at $25^{\circ} \mathrm{C}$. Left: Capric acid $80 \mathrm{mM}$; right: $\mathrm{C} 10 \mathrm{mix} 80 \mathrm{mM}$. The solid lines are fits to the data as described in the "Experimental" section.

\section{Results and Discussion}

\section{Vesicle stability at ambient temperature}

230 First, we studied the two model systems, capric acid and $\mathrm{C} 10 \mathrm{mix}$, at room temperature $\mathrm{T}=25{ }^{\circ} \mathrm{C}$. Because only the general features (vesicle presence and amount, bilayer thickness, micelle presence and amount) were investigated at this stage, the samples were extruded through a $100 \mathrm{~nm}$ polycarbonate membrane, in order to obtain a suspension of monodisperse vesicles. We verified that the use of bicine as buffer, commonly used in previous work with similar systems ${ }^{16,18,23,24}$, did not affect vesicle stability and properties at ambient temperature. This was done by screening a number of concentrations and $\mathrm{pH}$ conditions of the samples in buffered solution with Static Light Scattering (SLS) (Figure 1S, Supp. Info). Our results show a well defined vesicle population only at the lowest measured $\mathrm{pH}(7.8)$ and the highest concentration $(80 \mathrm{mM})$ data for the capric acid sample, while in the $\mathrm{C} 10 \mathrm{mix}$ the same is found also at higher $\mathrm{pH}$ (up to 11.5) and lower concentration (down to $40 \mathrm{mM}$ ).

240 These are qualitatively consistent with what was previously found for the $\mathrm{pK}_{\mathrm{a}}$ and the CVC of similar samples (pure capric acid and C10 mix 10:1 acid: alcohol ratio) that were suspended and titrated in water ${ }^{5,7}$. The bicine buffer did not lead to any significant variation in the behaviour of the model vesicles.

Dynamic Light Scattering (DLS) was then used as a tool to disentangle populations of very different sizes (from tens of nanometers to micrometers), allowing for the detection of the presence of micelles and vesicles. By fitting the autocorrelation curves considering one (or two) populations of scatterers, we can show that under very alkaline conditions $\left(\mathrm{pH}>>\mathrm{pK}_{\mathrm{a}}\right)$, micelles are detected in pure capric 
acid samples while for the $\mathrm{C} 10$ mix only vesicles are visible at every measured condition $(\mathrm{pH}, \mathrm{T})$ (Figure 2;
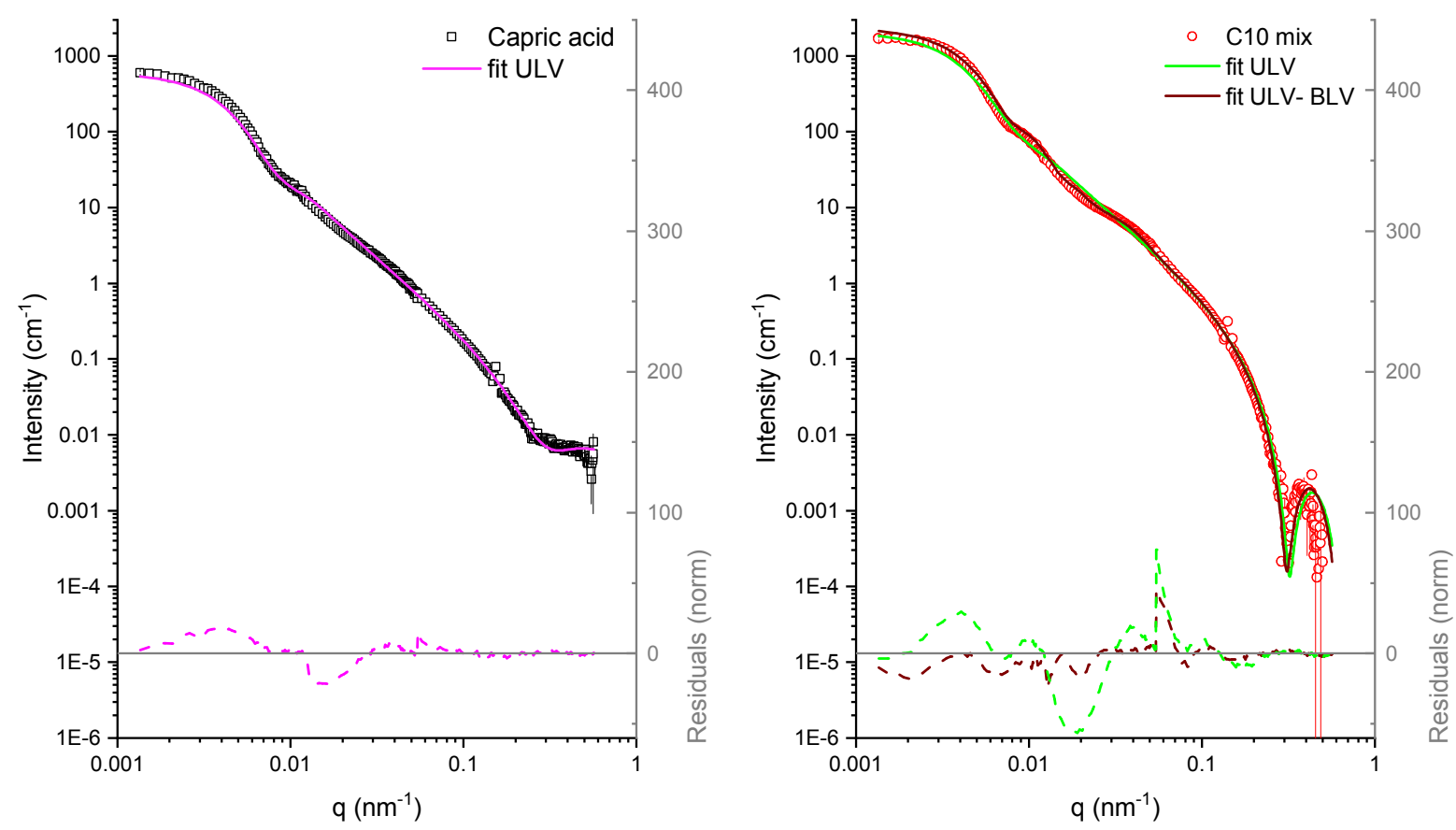

Figure 3. SANS curves of capric acid sample $80 \mathrm{mM}$ (left) and $\mathrm{C} 10 \mathrm{mix} 80 \mathrm{mM}$ (right) at $25^{\circ} \mathrm{C}$ collected on D33, and corresponding fits. Sample pH: 7.3 (capric acid) and 8.5 (C10 mix). For C10 mix, two models are compared and show that the pure unilamellar vesicle (ULV) model fails in describing correctly the features in the data, therefore a fraction of bilamellar vesicles (BLV) has to be added. The dotted lines are the normalised residuals in linear scale (right hand axis). The error bars are displayed only every 5 data points, for clarity.

data at $\mathrm{pH} 7.8$ and 8.1 are shown in Figure 2S, Supp. Info). We found for the micelles a mean diameter of 1-2 nm, consistent with the expected size of capric acid micelles.

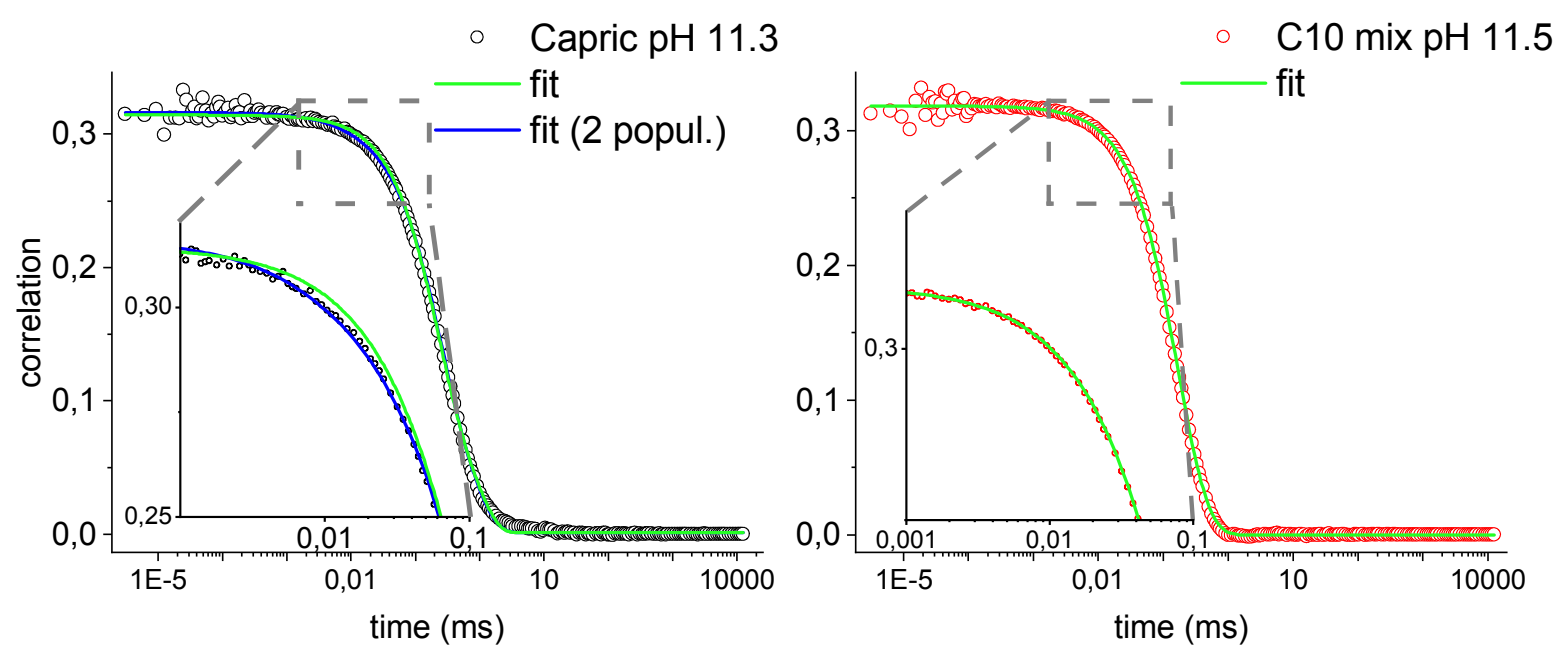

260 We thus kept a constant $\mathrm{pH}$ of 7.3 for the capric acid (to keep it nearby its $\mathrm{pK}_{\mathrm{a}}{ }^{25}$ ) and 8.5 for the $\mathrm{C} 10$ 
mix for the following Small-Angle Neutron Scattering (SANS) measurements. The vesicles made of pure capric acid present common features with those formed with the $\mathrm{C} 10 \mathrm{mix}$, as found from our SANS results and fits to the data (Figure 3 and Table 1; see the "Materials and methods" section for the fitting model formulas and Table $1 \mathrm{~S}$ for all used parameters, Supp. Info):

265 1. Both have vesicles with much smaller sizes than the extrusion pore diameter of $100 \mathrm{~nm}(59.6 \mathrm{~nm}$ and $80.6 \mathrm{~nm}$ diameter composed by $2 \mathrm{x}$ (core radius + shell thickness)), although the $\mathrm{C} 10 \mathrm{mix}$ vesicles have a larger mean radius;

2. A membrane thickness of about $2 \mathrm{~nm}$, as expected for a bilayer of amphiphiles with $1 \mathrm{~nm}$ chain length.

270 The following major differences are visible and inform about the substantial impact of the alcohol insertion. First, because the SANS data are very sensitive to the vesicle lamellarity, it is observed that, while the capric acid vesicles are always unilamellar, the C10 mix presents a fraction of bilamellar vesicles (BLV). Although the extrusion performed in this experiment could have interfered with the capability to form multilamellar structures in both samples, the data suggest a higher propensity of the

275 latter (C10 mix) to form membrane stacks. This will be further confirmed also on non-extruded samples, as discussed in the next section.

The observed bilamellar vesicles differ substantially from ordinary phosphatidylcholine (PC) MLVs for what concerns the water layer thickness $(11.8 \mathrm{~nm}$ for the $\mathrm{C} 10 \mathrm{mix}$, Table 1) between the lamellae, and their characteristics resemble more the typical values found at maximum swelling for charged

280 lipids in pure water ${ }^{29}$, while for PC lipids the solvent layer thickness is usually within 2-3 nm (DMPC, DPPC, DOPC, POPC) ${ }^{26-28}$.

As another main difference, according to the fit to the SANS data in absolute scale, we find that only $\approx 30 \%$ of the sample in the pure capric acid solution contributes to the vesicle form factor, even if it is close to its $\mathrm{pK}_{\mathrm{a}}$. This gives a second piece of indirect evidence about the main fraction of the FA $(\approx$ $65-70 \%$ ) remaining in solution as monomers or self-assembling into micelles. For the $\mathrm{C} 10 \mathrm{mix}$ sample, we observe that the totality of the sample (i.e. both the capric acid and the decanol), 
assembles

into

the

vesicles.
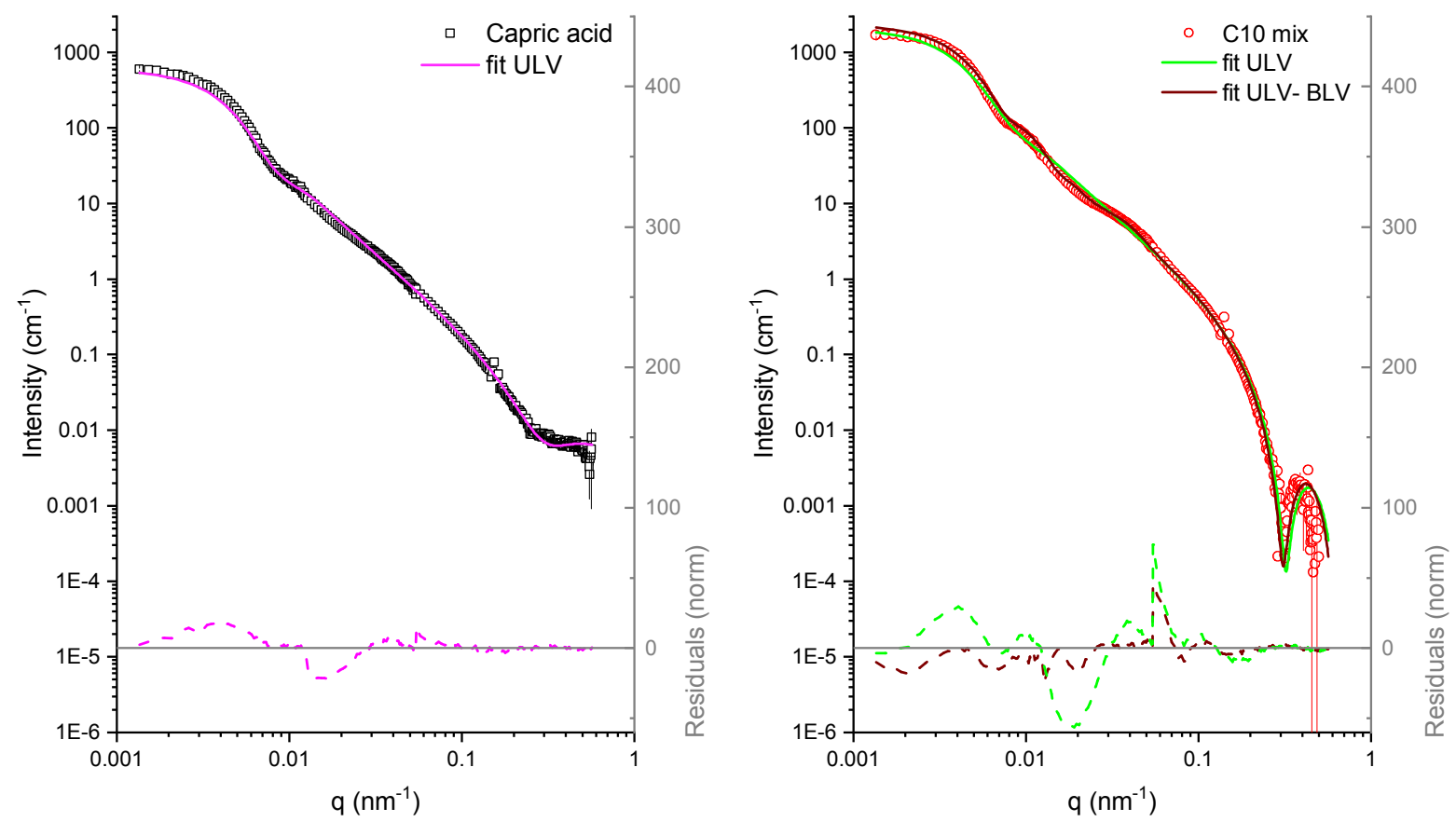

We conclude that the

Capric acid

C10 mix

addition of alcohol

brings

many

scale (total)

population fraction

core radius $(\mathrm{nm})$

shell thickness (nm)

solvent thickness (nm)

range of vesicle

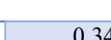

\begin{tabular}{|c|c|c|}
\hline 0.34 & \multicolumn{2}{|c|}{1} \\
\hline 1 & $0.6(\mathrm{ULV})$ & $0.4(\mathrm{BLV})$ \\
\hline 28.0 & 38.3 (ULV) & $9.2(\mathrm{BLV})$ \\
\hline 1.8 & $2.0(\mathrm{ULV})$ & $2.0(\mathrm{BLV})$ \\
\hline----- & ----- & $11.8(\mathrm{BLV})$ \\
\hline
\end{tabular}

295 by ${ }^{7,18}$ ). The totality of

mixture assembles into vesicles and leads to bigger, and in some cases multilayered, structures. No sign of micelles or monomers in solution (FA nor alcohol) is detected in the C10 mix, as opposed to the pure capric acid sample where only a small sample fraction aggregated into vesicles. 
Table 1. Main parameters extracted from the SANS data fitting at ambient temperature. Sample pH: 7.3 (capric acid) and 8.5 (C10 mix). Note, in particular, the scale factor of 0.34 calculated for the capric acid, a sign that only a fraction of sample contributes to the vesicle form factor. Full parameter list in Table 1S (Supp. Info).

305

\begin{tabular}{r|c|c|c|} 
& \multicolumn{2}{c}{ Capric acid } & \multicolumn{2}{c}{ C10 mix } \\
\hline scale (total) & 0.34 & & $0.4(\mathrm{BLV})$ \\
\cline { 2 - 4 } population fraction & 1 & $0.6(\mathrm{ULV})$ & \\
\cline { 2 - 4 } core radius $(\mathrm{nm})$ & 28.0 & $38.3(\mathrm{ULV})$ & $9.2(\mathrm{BLV})$ \\
\cline { 2 - 4 } shell thickness $(\mathrm{nm})$ & 1.8 & $2.0(\mathrm{ULV})$ & $2.0(\mathrm{BLV})$ \\
\cline { 2 - 4 } solvent thickness $(\mathrm{nm})$ & ---- & ---- & $11.8(\mathrm{BLV})$ \\
\cline { 2 - 4 } & & &
\end{tabular}

\section{Thermal stability}

The vesicle thermal behaviour was explored by means of Differential Scanning Calorimetry (DSC, solid lines in Figure 4) and DLS (symbols in Figure 4) to explore membrane phase transitions (DSC) and follow vesicle dimension evolution (DLS). For all the experiments in this section, the $\mathrm{pH}$ of capric acid and $\mathrm{C} 10$ mix were set to 7.7 and 8.5 , respectively. Because the focus here was to screen the mean vesicle size with temperature and to detect the gel-fluid membrane phase transition, the samples were extruded prior to the experiments.

The DSC thermogram of $\mathrm{C} 10$ mix vesicles shows a first sharp transition at $10.3{ }^{\circ} \mathrm{C}$ assigned to the gel-fluid membrane phase transition and a second, much broader one, detected above $60{ }^{\circ} \mathrm{C}$. This result is consistent with what was observed previously ${ }^{18}$. The latter transition, for $\mathrm{T} \geq 60{ }^{\circ} \mathrm{C}$, was interpreted by ${ }^{18}$ as a conformational micelle-vesicle equilibrium change. Here we additionally investigated pure capric acid vesicles and observed a single sharp transition at $13.9{ }^{\circ} \mathrm{C}$ but no sign of a second broad one.

For this reason, the high-temperature broad transition does not seem linked to a vesicle - micelle equilibrium shift as previously proposed. 


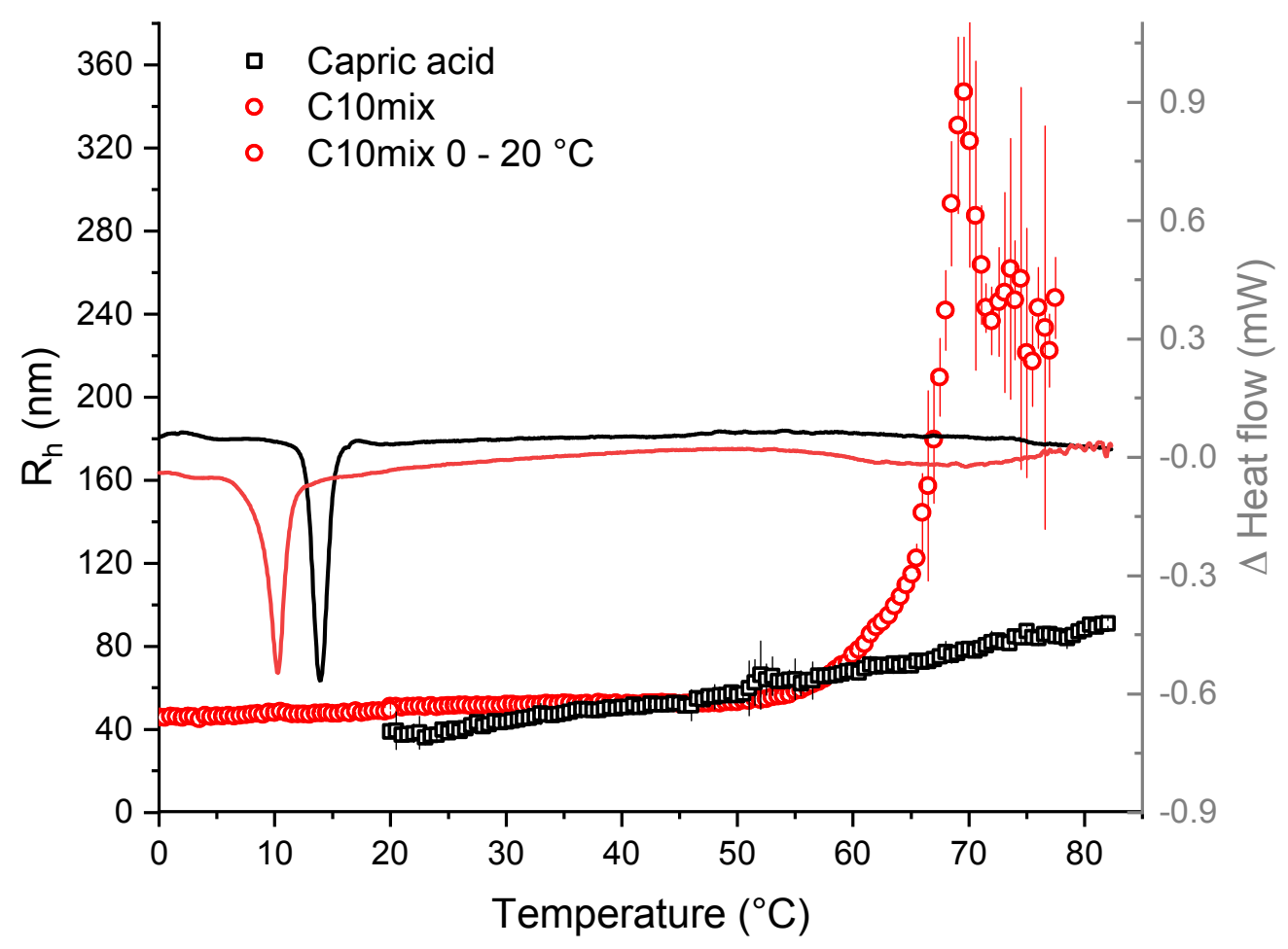

Figure 4. Left axis: Resulting Rh found from fitting the DLS autocorrelation functions at a fixed angle $\left(90^{\circ}\right)$ as function of the temperature, for the pure capric acid at $80 \mathrm{mM}$ (black squares) and $\mathrm{C} 10 \mathrm{mix}$ at $80 \mathrm{mM}$ (red circles). The additional dataset collected for $\mathrm{C} 10 \mathrm{mix}$ in the range $0-20{ }^{\circ} \mathrm{C}$ proves that there is no effect of the gel-fluid phase transition in the vesicle size, as expected. Right axis: DSC thermograms of the same samples (red and black lines).

The capric acid sample is in fact the only one giving evidence for the presence of micelles (observed directly in our DLS data and indirectly in our SANS data as a lack of the expected vesicle signal, Figure 2 and Table 1). Furthermore, our DLS data vs T (Figure 4, symbols) show a corresponding, 335 steep increase in the mean vesicle radius occurring at the same temperature and only for the $\mathrm{C} 10 \mathrm{mix}$. This, together with the marked difference with the pure capric acid vesicles, suggests that the observed high temperature effect is an alcohol triggered phase transition towards bigger macrostructures.

The thermal behaviour of the samples was also addressed by performing solid-state (ss) ${ }^{2} \mathrm{H}-\mathrm{NMR}$ and 340 SANS as a function of temperature for capric acid and C10 mix water dispersions. In this case, the samples were not extruded to avoid interferences in the samples lamellarity. ssNMR was used to bring quantitative structural and dynamic information about the dispersions, as has been accomplished long ago on liquid-crystal-like assemblies such as biological membranes, lipids, colloids and surfactants dispersed in water ${ }^{30-32}$. In our case, perdeuterated capric acid was used in order to probe the membrane dynamics (experimental details and ssNMR data analysis can be found in the Supp. Info). 
Figure 5 shows some wide-line spectra recorded for a few temperatures for capric acid and C10 mix water dispersions.
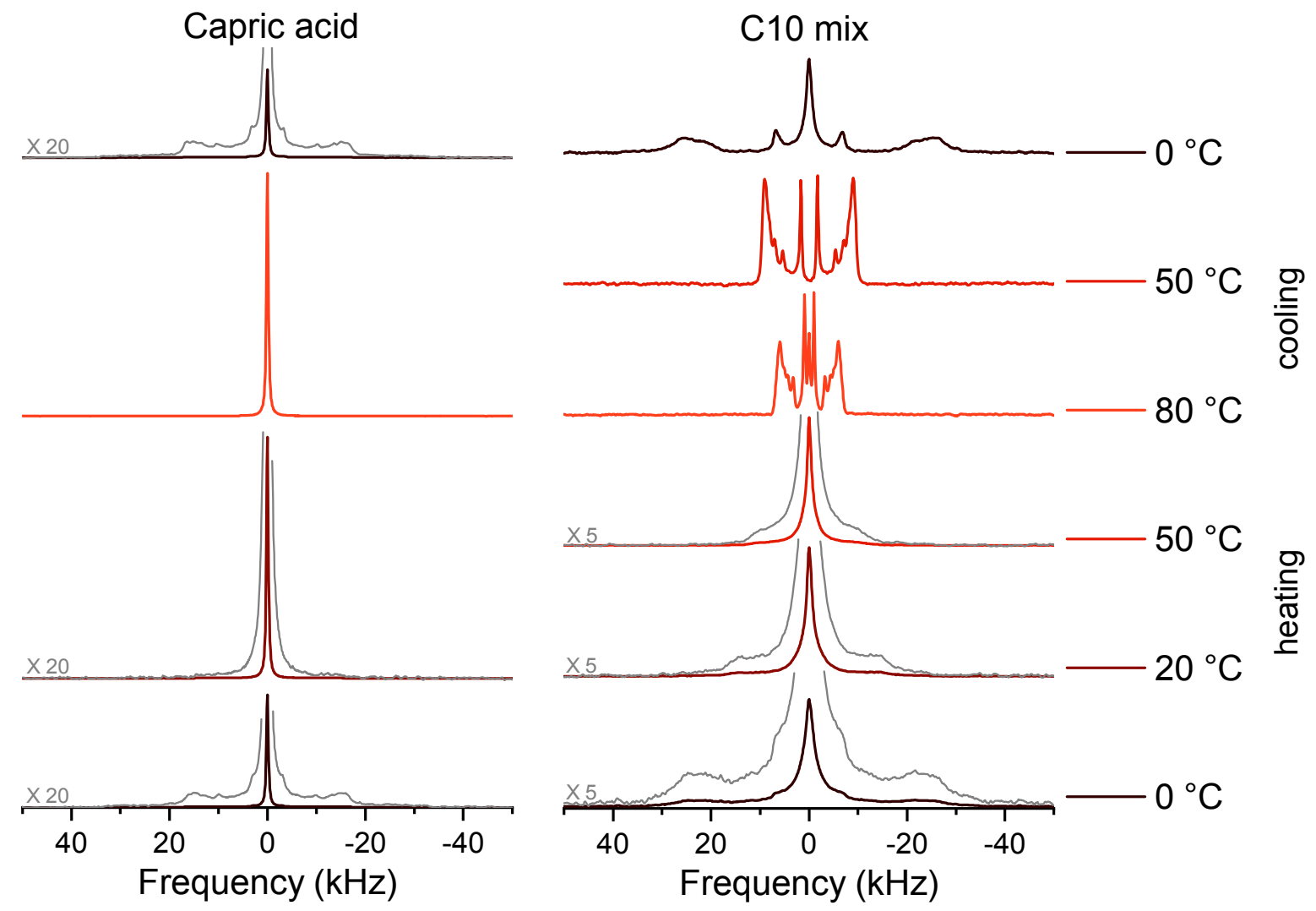

Figure 5. ${ }^{2} \mathrm{H}_{19}$-ssNMR spectra of ${ }^{2} \mathrm{H}_{19}$-capric acid $350 \mathrm{mM}$ (left) and ${ }^{2} \mathrm{H}_{19}$-capric acid:decanol $350 \mathrm{mM}$ (right) water dispersions ( $94 \%$ and $95 \%$ hydration, respectively) as a function of temperature, from bottom to top, on increasing the temperature from 0 to $80^{\circ} \mathrm{C}$ and cooling back to 50 and $0{ }^{\circ} \mathrm{C}$. Grey solid lines show details of the baseline by multiplying the vertical scale by 20 (left) and 5 (right). 


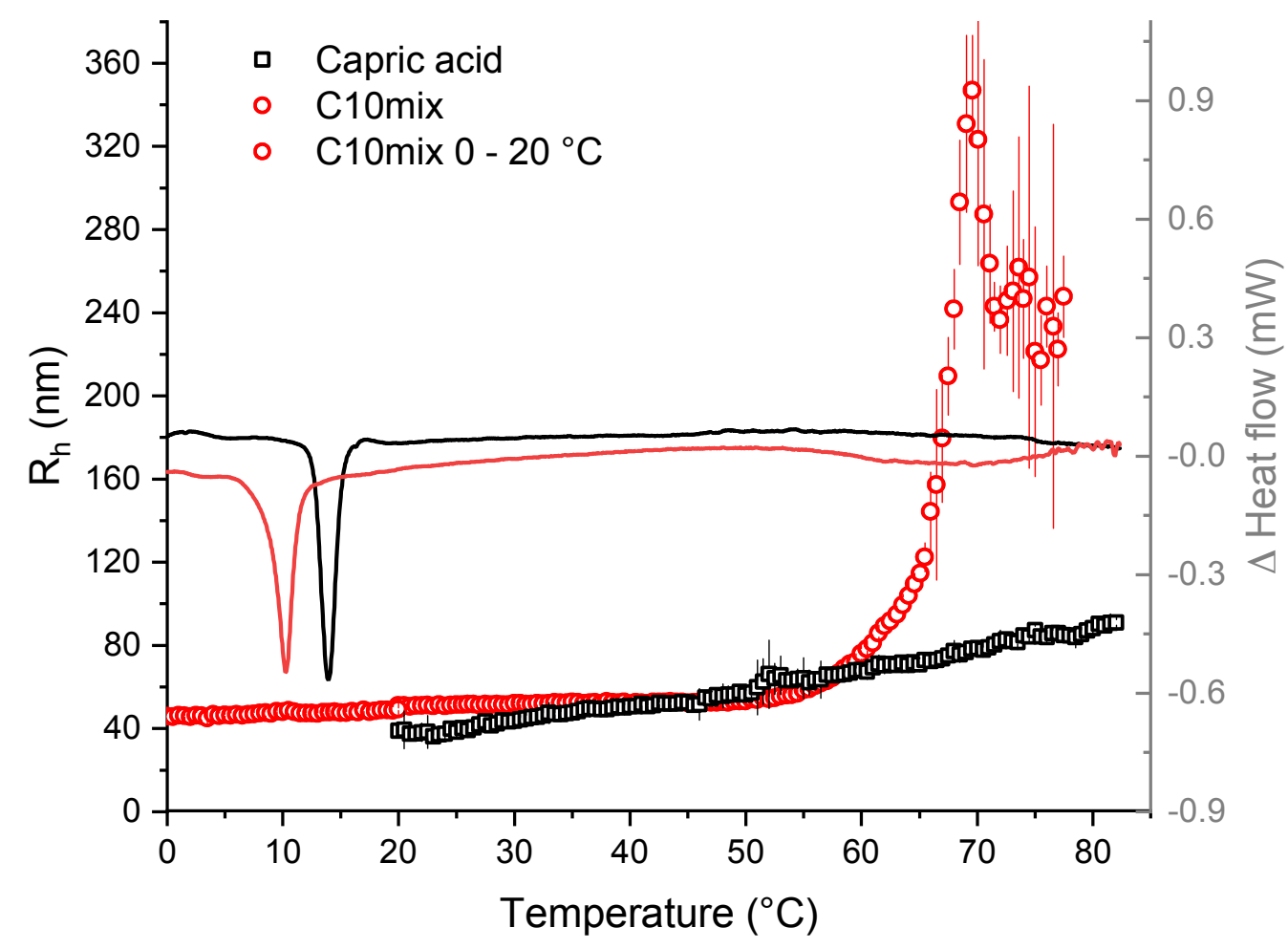

In the capric

acid data (left of Figure 5), an isotropic very intense Lorentzian line dominates most spectra from 0

${ }^{\circ} \mathrm{C}$ to $80{ }^{\circ} \mathrm{C}$ indicative of small size objects (1-100 nm) tumbling very fast compared to the ssNMR time scale ${ }^{33}$. Close attention to the spectrum at $0{ }^{\circ} \mathrm{C}$ allows detection of a so-called "powder" (nonoriented) pattern indicating that slowly tumbling much larger objects (microns to submicron size) are also identified. At the other temperatures, there is no sign of large objects in the capric acid sample.

Conversely, in the case of the C10 mix (right set of curves in Figure 5) the coexistence of broad 360 powder patterns and isotropic lines is observed at all temperatures, and the latter is much less abundant as was the case in the former sample. This points again towards a higher propensity of the alcohol-enriched vesicles to maintain the big multilayer structures. The hydrophobic bilayer thickness $\left(b_{\mathrm{H}}\right)$ at $\mathrm{T}=20^{\circ} \mathrm{C}$, calculated from the NMR spectral simulations assuming no chain interdigitation, was $b_{\mathrm{H}}=2 * \mathrm{~L}_{\text {chain }}=(1.66 \pm 0.08) \mathrm{nm}$ (Table $3 \mathrm{~S}$, Supp. Info). This value is slightly lower than the one 365 found from SANS fitting, $b=(2.0 \pm 0.1) \mathrm{nm}$ (Table 1 and Table 1S, Supp. Info), and the discrepancy may reflect twice the size of the small FA headgroup, $\left(b-b_{H}\right) / 2=(2.0-1.66) n m / 2 \approx 0.17 \mathrm{~nm}$. 

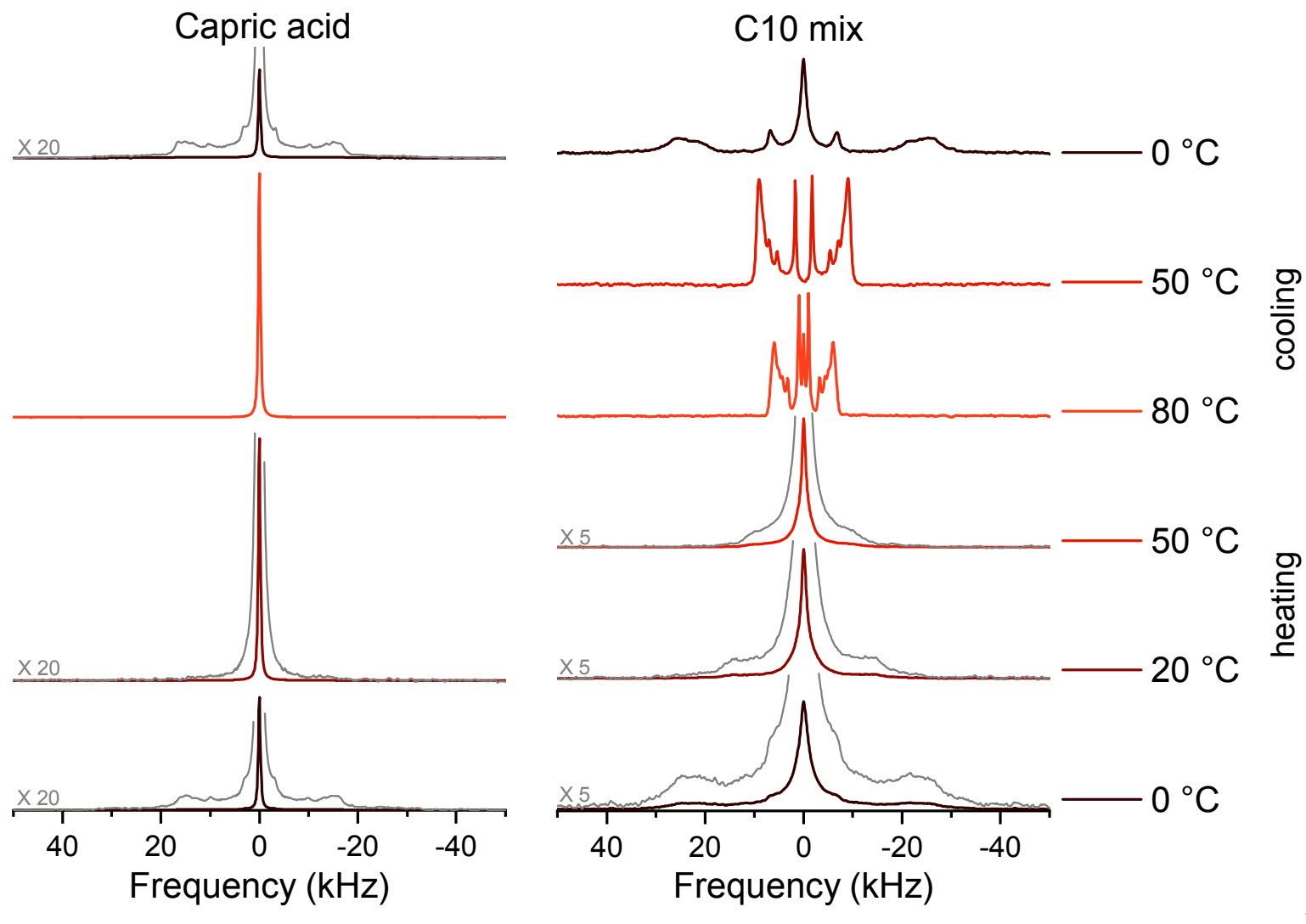

$\mathrm{Fi}$

nally, the spectrum of the $\mathrm{C} 10$ mix at $80^{\circ} \mathrm{C}$ (hence above the conformational transition seen at $\mathrm{T} \geq 60$ ${ }^{\circ} \mathrm{C}$, Figure 4) shows an oriented-like pattern (bilayer normal perpendicular to the magnetic field of the spectrometer). Returning to $50{ }^{\circ} \mathrm{C}$ shows the same but wider oriented-like pattern, that differs considerably (the isotropic line is absent) from that observed on increasing temperature. Returning further to $0{ }^{\circ} \mathrm{C}$ shows a superimposition of powder pattern and isotropic lines with, however, a lower proportion (Figure 5S, Supp. Info). This clearly indicates a hysteresis related to the thermal history of the sample suggesting intense thermally induced sample reorganization.

375 We questioned whether the addition of decanol triggered a transition from a lamellar to a non-lamellar phase, e.g. hexagonal or cubic, as these can grow with a preferential direction and lead to NMR spectra such as the one observed for the $\mathrm{C} 10 \mathrm{mix}$ at $80^{\circ} \mathrm{C}$ (inverted phases being improbable because of the low amphiphile concentration used). For that, we performed SANS experiments on the same samples.

380 At high $\left(\mathrm{D}_{2} \mathrm{O}\right)$ contrast, SANS is extremely sensitive to the presence and dimensions of MLVs and ULVs (LUVs and SUVs), and to small spherical or elongated micelles, as their dimensions are within the q-range of interest in this study $\left(1.5 \times 10^{-3}\right.$ to $0.6 \AA^{-1}$, which corresponds in real space to dimensions of 420 to $1 \mathrm{~nm}$ ). The multilamellar structures can be studied following the correlation between the adjacent membranes (given by the static structure factor $\mathrm{S}(\mathrm{q})$ ) ${ }^{34}$. For instance, the relative position 385 between the oscillation' maxima, observed as broadened peaks in the SANS curves, will differ for 
lamellar (positions $n, 2 n, 3 n \ldots, n$ being the order) or hexagonal $(n, \sqrt{ } 3 n, 2 n \ldots)$ phases ${ }^{35}$. Thus, this represents a convenient way to distinguish between lamellar and non-lamellar phases.

Additionally, even in the cases where there is no phase ordering and the correlations are absent (so that $\mathrm{S}(\mathrm{q})=1$ over the entire $\mathrm{q}$-range and no structure peak is observed), it is still possible to 390 distinguish, from the decay of the curves (representing the form factor $\mathrm{P}(\mathrm{q})$ ), between planar lamellae and solid
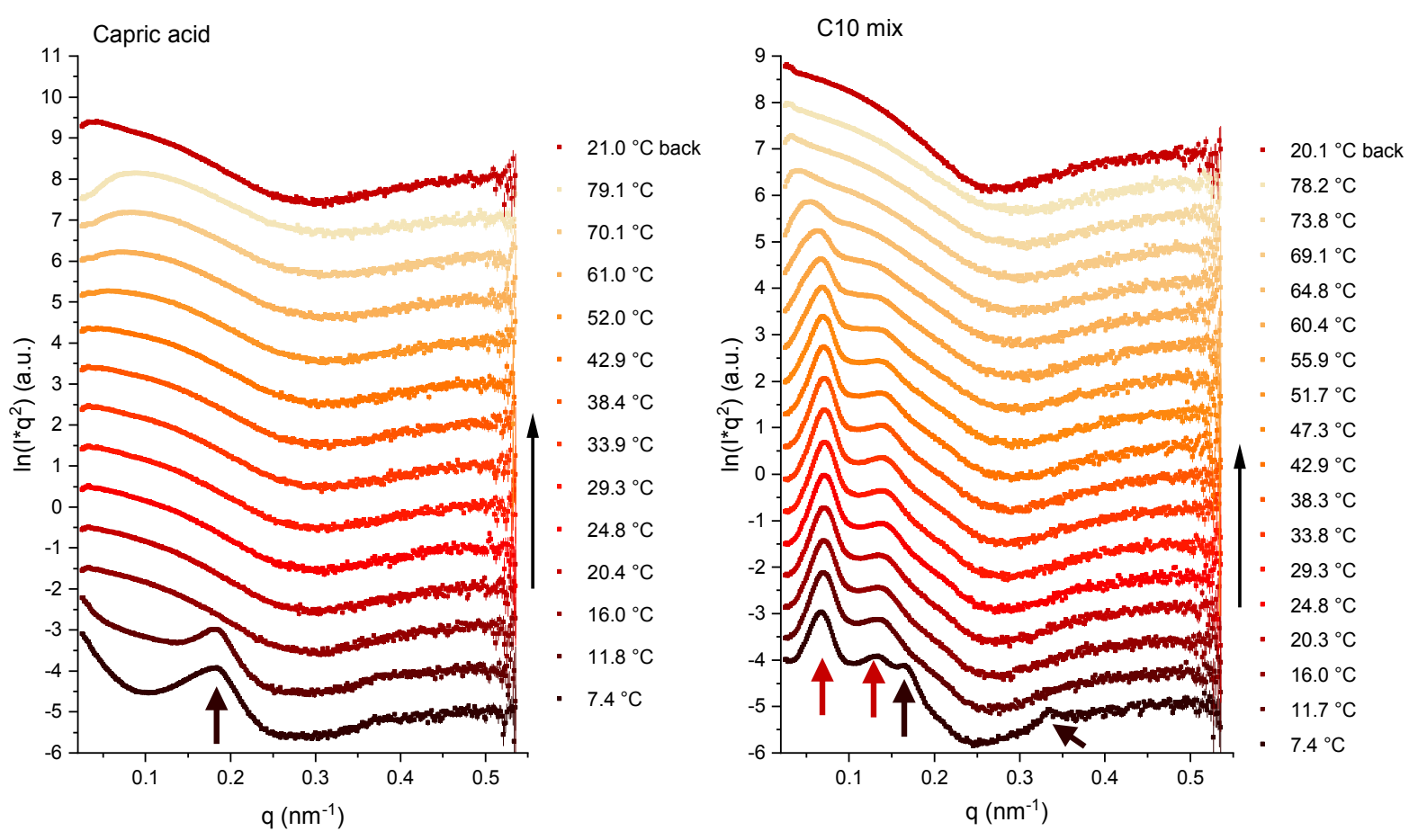

Figure 6. SANS curves at different temperatures collected on D16, shown in the representation $\ln \left(I^{*} \mathrm{q}^{2}\right)$ vs $\mathrm{q}$, to highlight the presence of membrane correlations. This representation should flatten the curves that have the typical decay of vesicles $\left(\mathrm{q}^{-2}\right)$ Left: Capric acid sample $350 \mathrm{mM}$. Right: C10 mix sample $350 \mathrm{mM}$. Arrows show the first two orders of the observed lamellar phases structure factor $\mathrm{S}(\mathrm{q})$.

cylinders, characteristic of elongated micelles (the hexagonal phase "building blocks", diluted and free to move in solution) ${ }^{36}$. The planar lamellae would decay with $\mathrm{a} \approx \mathrm{q}^{-2}$ power decay, while for cylinders the decay would follow $\mathrm{a} \approx \mathrm{q}^{-1}$ decay.

400 The SANS curves were collected for both the capric acid and C10 mix samples as a function of temperature in the range $7-80{ }^{\circ} \mathrm{C}$ (Figure 6). All the curves show a decay close to a $\mathrm{q}^{-2}$ power decay, indicating the presence of vesicles. The capric acid vesicles (left plot of Figure 6) possess a correlation peak at $\mathrm{q}=(1.8 \pm 0.1) \mathrm{nm}^{-1}$ that corresponds to a d-spacing of $(3.4 \pm 0.1) \mathrm{nm}$. This correlation disappears at $16{ }^{\circ} \mathrm{C}$ and no other correlation is visible at higher temperatures. From 16 to

$40543{ }^{\circ} \mathrm{C}$ the curves are identical. From $52{ }^{\circ} \mathrm{C}$ on, a change is observed in the low q region. Remarkably, the fits performed on the capric acid curves for $\mathrm{T} \geq 16{ }^{\circ} \mathrm{C}$ show the need to consider a model of vesicles coexisting with micelles to properly reproduce the experimental data (Table 4S, Supp. Info). 
In Figure 7 some of the fits are shown, as well as the normalised respective fraction corresponding to each species (Figure 7 , right panel). At $\mathrm{T} \leq 35{ }^{\circ} \mathrm{C}, \approx 85 \%$ of capric acid contributes to the vesicle micelles.
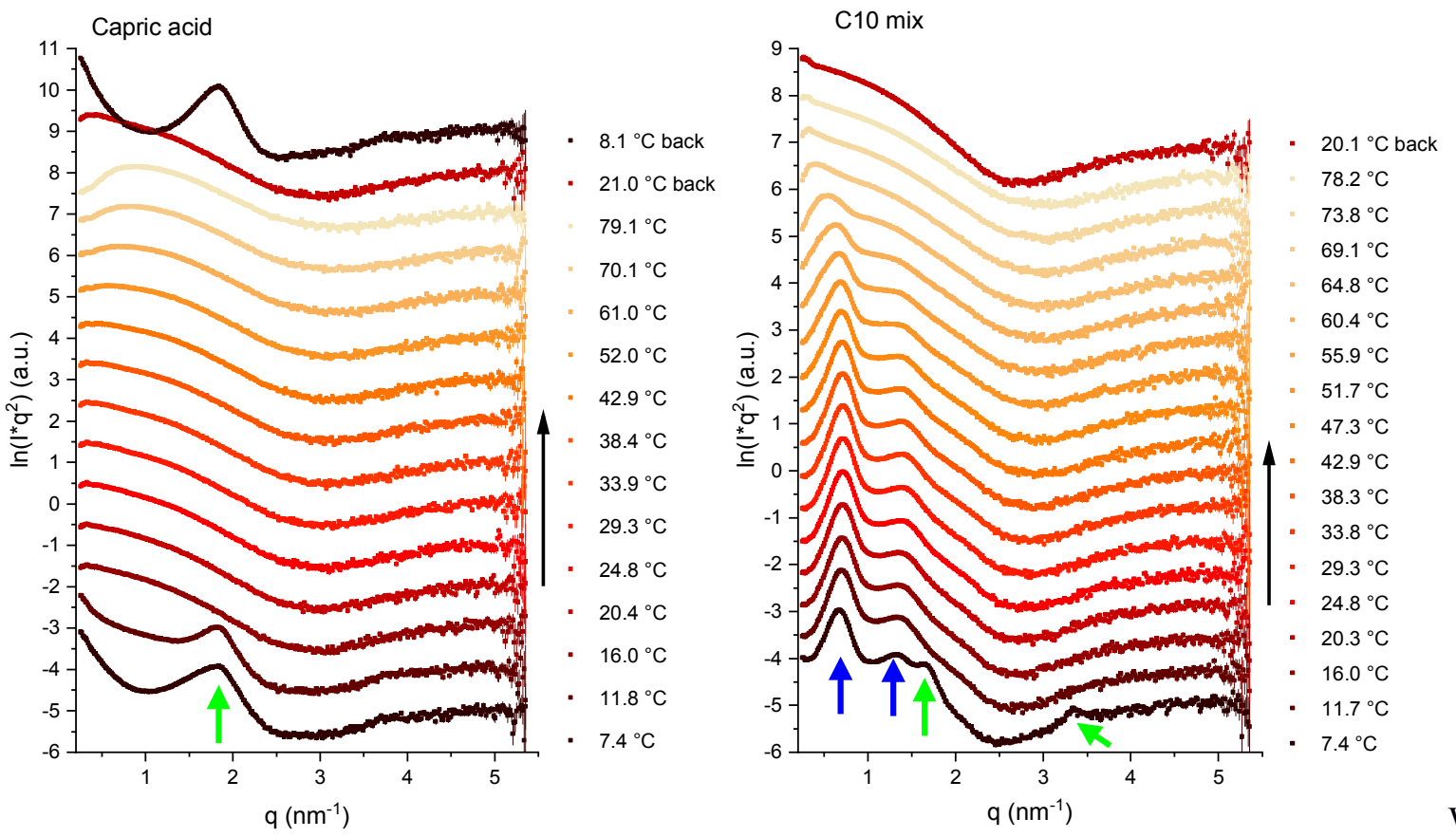

hen $\mathrm{T} \geq 35^{\circ} \mathrm{C}$, a steep decrease in vesicle amount is observed, followed by a concomitant increase in the micelle signal. The sum of the two components also goes slightly down with the temperature 

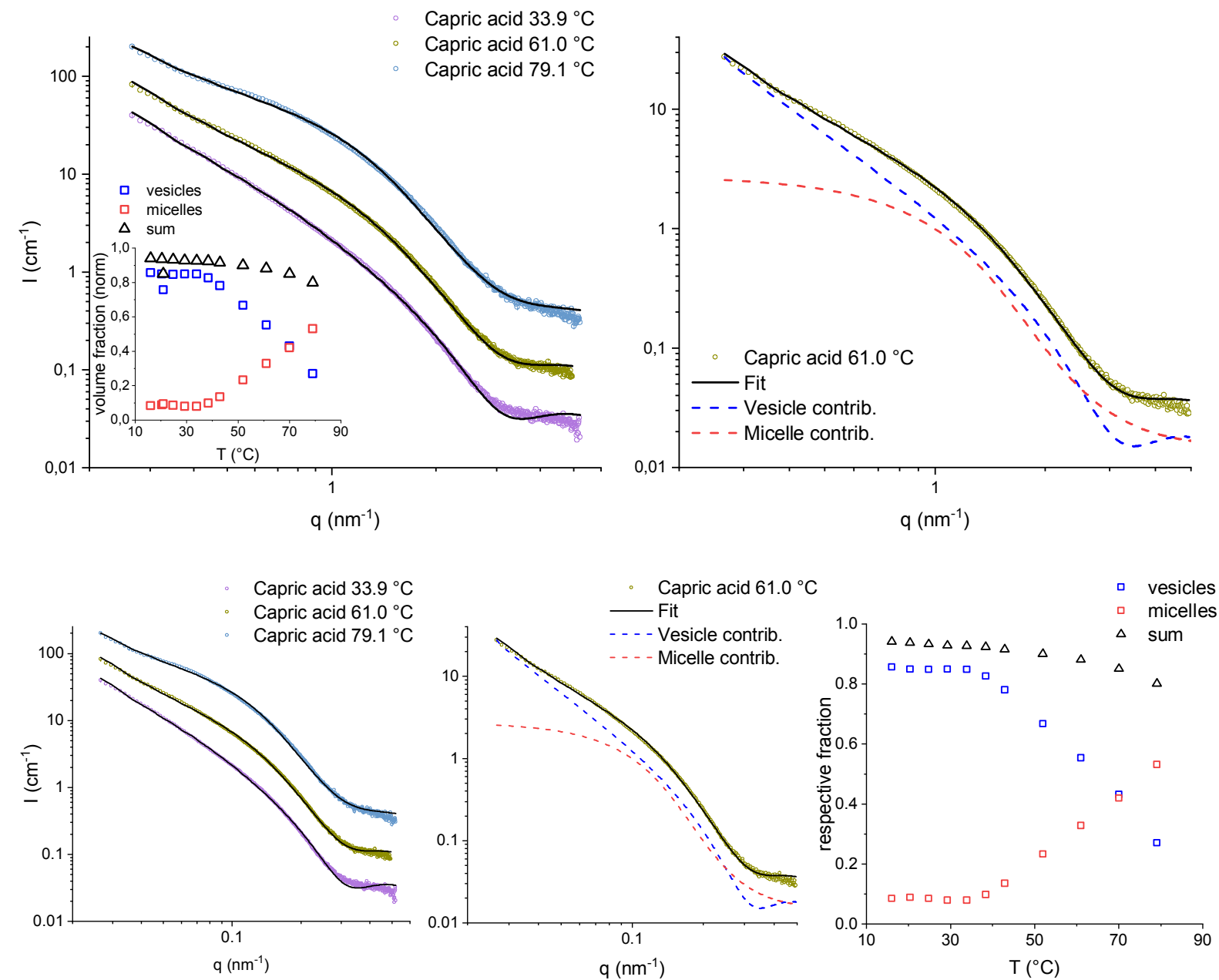

Figure 7. Left: Examples of fits performed on the capric acid SANS data from D16. The error bars are displayed every 5 data points. Middle: Plot of the vesicle and micelle contributions and their sum for $\mathrm{T}=61{ }^{\circ} \mathrm{C}$. Right: Respective fraction of vesicles and micelles.

420 Upon cooling back to $20^{\circ} \mathrm{C}$, the proportion of micelles and vesicles is recovered but the total amount of self-assembled material is diminished, which may be a sign of the occurrence of some phase separation. Finally, cooling down to $8{ }^{\circ} \mathrm{C}$ causes the complete recovery of the correlation peak (data not shown). 

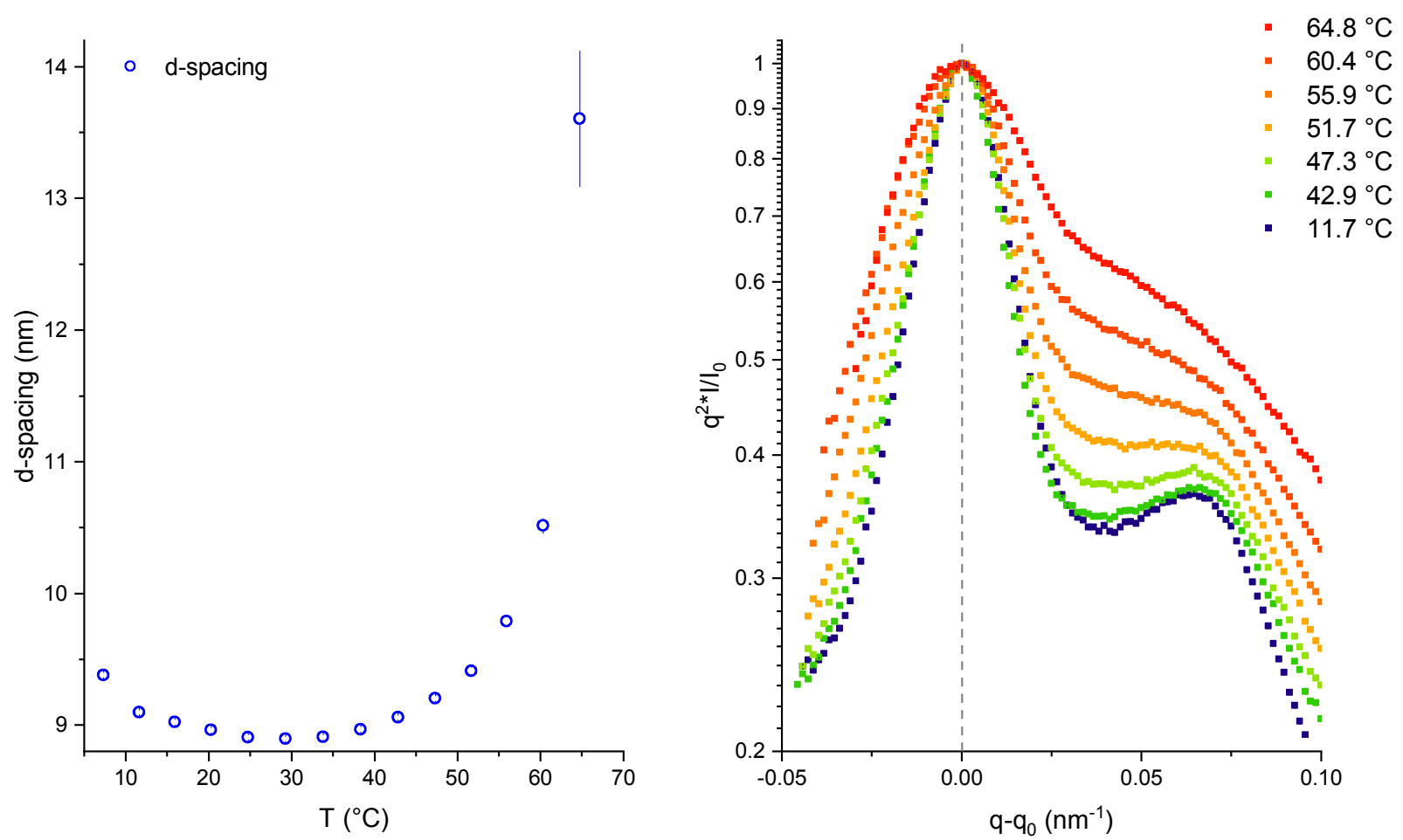

425 On the other hand, the correlation peaks observed in the C10 mix (right plot of Figure 6) show that the sample is biphasic at low temperature $\left(7^{\circ} \mathrm{C}\right)$ : the first phase has a correlation at $\mathrm{q}=(0.7 \pm 0.1) \mathrm{nm}^{-1}$ (d-spacing of $(9.4 \pm 0.1) \mathrm{nm})$, the second at $\mathrm{q}=(1.70 \pm 0.1) \mathrm{nm}^{-1}(\mathrm{~d}$-spacing $=(3.7 \pm 0.1) \mathrm{nm})$. Since the second order peaks are visible for both correlations at $2^{*} \mathrm{q}_{\mathrm{i}}$, we are in the presence of two coexisting lamellar phases. Above $10{ }^{\circ} \mathrm{C}$, only the swollen phase is visible, at $\mathrm{q}=(0.7 \pm 0.1) \mathrm{nm}^{-1}(\mathrm{~d}-$ 430 spacing $=(9.4 \pm 0.1) \mathrm{nm})$. The gel-fluid phase transition of the $\mathrm{C} 10 \mathrm{mix}$, occurring at $\mathrm{T}=10^{\circ} \mathrm{C}$ (DSC thermogram of Figure 4$)$, can explain the slight decrease $(\approx 0.5 \mathrm{~nm})$ in the d-spacing of the swollen phase from 7 to $30^{\circ} \mathrm{C}$ as a thinning of the bilayer upon melting (Figure 8, left). Remarkably, the dspacing decrease of $\Delta \mathrm{d}=(0.42 \pm 0.03) \mathrm{nm}$ from 7 to $20^{\circ} \mathrm{C}$ is in extremely good agreement with the decrease in hydrophobic bilayer thickness $\left(\Delta b_{H}\right)$ as calculated from the NMR spectral simulations, $435 \Delta \mathrm{b}_{\mathrm{H}}=(0.44 \pm 0.11)$ (Supp. Info). Approaching the second phase change (above $\left.50-60{ }^{\circ} \mathrm{C}\right)$, the membrane phase undergoes a fast swelling (now due to the water layer thickening between membranes) seen as a shift of the correlation towards lower q, until disappearing. This effect was observed in the literature and referred to as an unbinding transition ${ }^{29,37}$. Both the $\mathrm{C} 10$ mix curves at the highest temperature $\mathrm{T}=78{ }^{\circ} \mathrm{C}$ and after cooling back to $\mathrm{T}=20{ }^{\circ} \mathrm{C}$ fit extremely well with a 440 bilayer form factor, with $\mathrm{a} \approx \mathrm{q}^{-2}$ decay (Figure 9 and Table 5S, Supp. Info). This decay is much different from the one that would be observed in the case of elongated cylindrical micelles, with $\approx 1$ $\mathrm{nm}$ radius (plotted as a grey dashed line in Figure 9). These results indicate that the high temperature structure of the $\mathrm{C} 10$ mix samples is still a unilamellar membrane. Interestingly, the two fitting results differ slightly in the bilayer thicknesses $\left(1.8 \mathrm{~nm}\right.$ at $85{ }^{\circ} \mathrm{C}, 2.1 \mathrm{~nm}$ at $20^{\circ} \mathrm{C}$, uncertainty $\left.0.1 \mathrm{~nm}\right)$ and their polydispersity $\left(0.27\right.$ at $85^{\circ} \mathrm{C}, 0.15$ at $\left.20^{\circ} \mathrm{C}\right)$. 

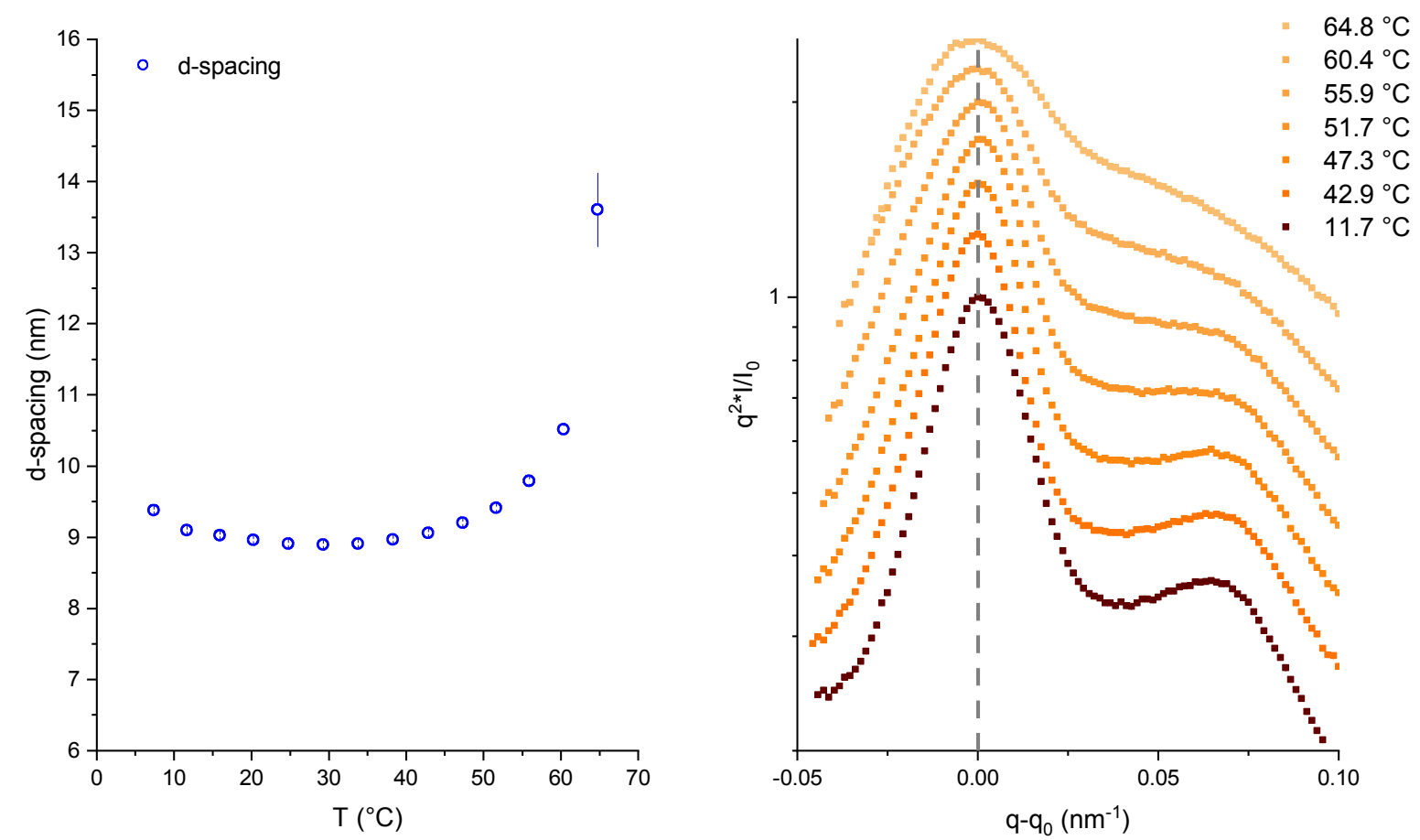

Figure 8. Left: $d$-spacing of the swollen C10 mix phase as function of T. Right: C10 mix SANS curves collected on D16, zoomed around the first lamellar correlation peak, in the representation $\mathrm{q}^{\wedge} 2 * \mathrm{I} / \mathrm{I}_{0}$ vs $\mathrm{q}-\mathrm{q}_{0}$ to highlight the $1^{\text {st }}$ and $2^{\text {nd }}$ order peak broadenings upon heating. Some of the curves at low temperature were skipped, for clarity.

These are in line with the consideration that the molten amphiphiles' chains allow a wider range of bent/kinked configurations at higher temperatures. Most importantly, no scaling factor is required to fit the two curves, which means that no amphiphile solubilization or disaggregation happens while the temperature is increased, unlike with the pure capric acid where progressive solubilization takes place 455 (Figure 7).

The experimental results lead towards a high temperature, alcohol-triggered phase transition occurring above $\mathrm{T}=60^{\circ} \mathrm{C}$ that leads to bigger structures still possessing a bilayer (Figure 9), which are oriented upon application of a magnetic field (Figure 5). Furthermore, the alcohol addition stabilizes the membrane by preventing a temperature induced vesicle dissolution into micelles.

460 The experimental results lead towards a high temperature, alcohol-triggered phase transition occurring above $\mathrm{T}=60^{\circ} \mathrm{C}$ that leads to bigger structures still possessing a bilayer (Figure 9), which are oriented upon application of a magnetic field (Figure 5). Furthermore, the alcohol addition stabilizes the membrane by preventing a temperature induced vesicle dissolution into micelles. 


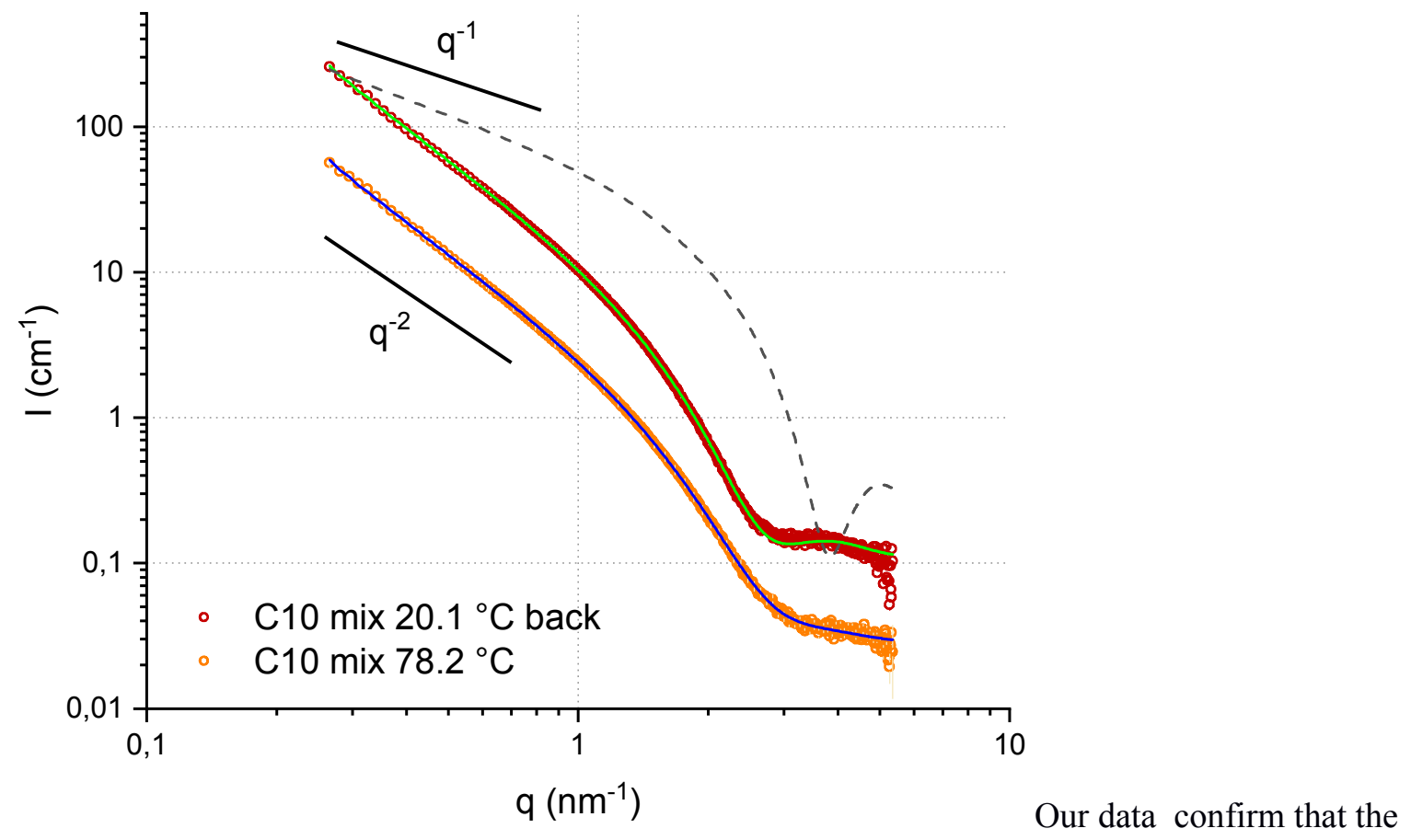

465 decanol addition has a marked stabilizing effect on the membrane at ambient temperature. In addition, we found additional measurable differences in the amphiphile behaviour that complement the 
previous findings ${ }^{7,18}$, such as:

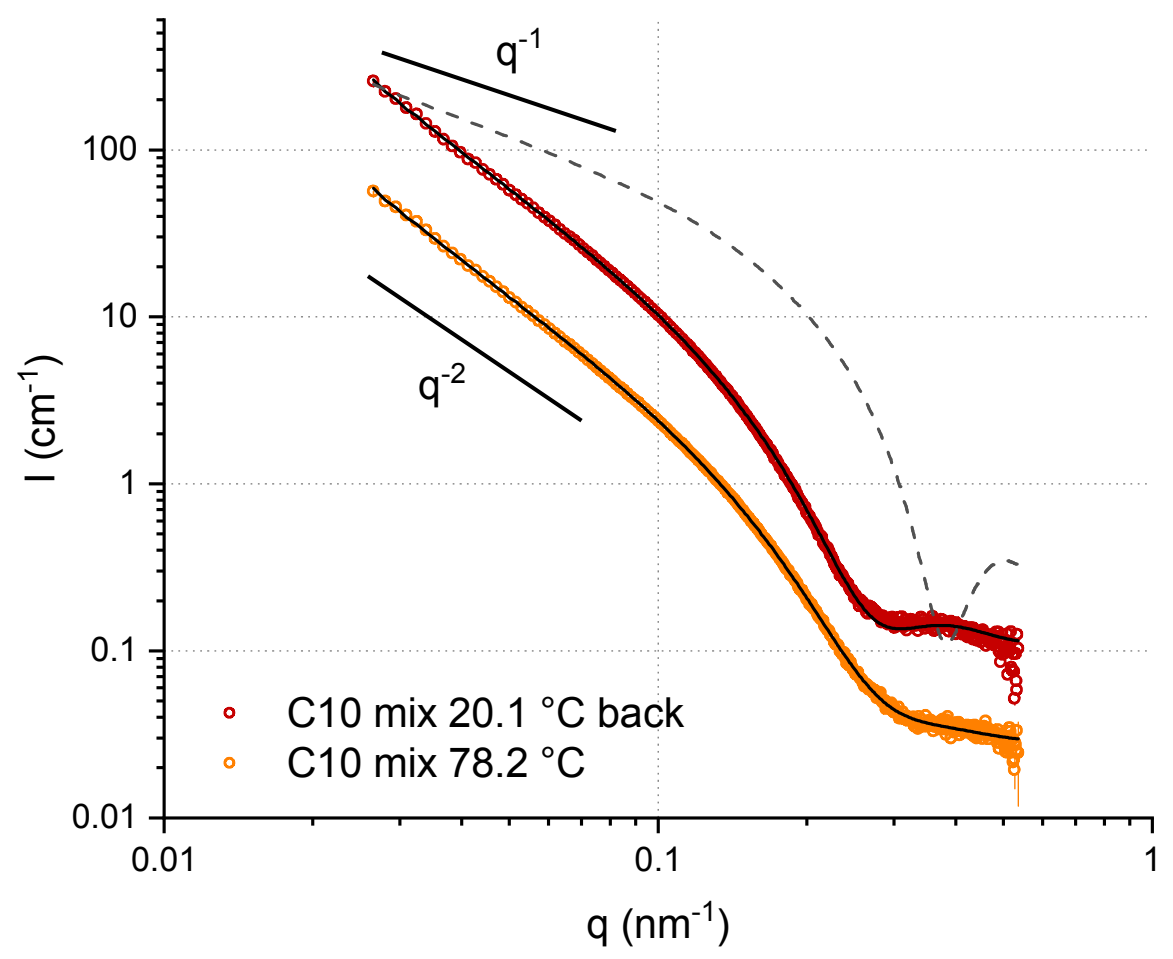

Figure 9. Results of fitting the SANS curves on D16 for $\mathrm{C} 10 \mathrm{mix}$ at $78.2{ }^{\circ} \mathrm{C}$ and cooled back to $20.1^{\circ} \mathrm{C}$, each with a bilayer model. The error bars are displayed every 5 data points, for clarity. The black dashed line shows the model of a system of elongated micelles with $1.0 \mathrm{~nm}$ radius and $100 \mathrm{~nm}$ length. The black straight lines show the $\mathrm{q}^{-1}$ and $\mathrm{q}^{-2}$ decay behaviours. Models considering vesicles or hollow cylinders, with core radius $\mathrm{R}>20$ $\mathrm{nm}$, could fit equally well the data in this q region.

a) A marked increase in the vesicle amount at the expense of micelles (Figure 2 and 3, Table 1);

b) A higher propensity to form bigger and multilamellar vesicles (Figure 3).Our data confirm that the decanol addition has a marked stabilizing effect on the membrane at ambient temperature. In addition, we found additional measurable differences in the amphiphile behaviour that complement the previous findings ${ }^{7,18}$, such as:

a) A marked increase in the vesicle amount at the expense of micelles (Figure 2 and 3, Table 1);

b) A higher propensity to form bigger and multilamellar vesicles (Figure 3). 
Apel and coworkers ${ }^{7}$ interpreted the stabilizing effect of the alcohol, for the vesicle self-aggregation at ambient temperature, in terms of hydrogen bonding. In particular, they measured quantitatively that the aggregates of ionic FAs-alcohols (giving vesicles) are thermodynamically more favourable than the FA hydrogen bonds with water that induce micelle formation or favour monomers in solution. This interpretation can explain our observed increase of the vesicle population at the expense of the micelles. However, this does not explain the higher propensity to form bigger, and even multilamellar structures. Our data imply that the alcohol must also affect considerably the amphiphile packing parameter ${ }^{38}$. Supposing the intrinsic geometry of the ionic FA as conic (because of the electrostatic repulsion of the anionic headgroups), the hydrogen bond with a neutral FA molecule leads to a geometry which is approaching the cylindrical one and therefore can allow for the formation of flat or low curvature aggregates like vesicles. Nevertheless, it is the ionic FA-alcohol aggregates that lead most effectively to a cylindrical intrinsic geometry, so that planar structures are more easily formed and much bigger multilamellar vesicles can be produced.

It is in the thermal behaviour that the two systems, differing by the presence of the alcohol, show the most remarkable distinctions, and some of them are found in the low temperature region. As shown in Figure 6, we observe for the capric acid at $\mathrm{T}<16{ }^{\circ} \mathrm{C}$ a single lamellar phase with a $\mathrm{d}$-spacing $=(3.4 \pm$ $0.1) \mathrm{nm}$, at a much lower value than that expected for the membrane correlation in a MLV. On the other hand, at $\mathrm{T}<11^{\circ} \mathrm{C}$ the $\mathrm{C} 10$ mix shows a coexistence of such collapsed phase (with slightly different $\mathrm{d}$-spacing $=(3.7 \pm 0.1) \mathrm{nm})$ with the expected MLV swollen phase $(\mathrm{d}$-spacing $=(9.4 \pm 0.1)$

$500 \mathrm{~nm}$ ). We interpret the occurrence of the collapsed phase as the probable crossing of the corresponding FA Krafft temperature (Figure 6S, Supp. Info), known as the temperature below which the surfactant solubility is below its critical micelle concentration (CMC), causing flocculation. Therefore, the observed transition at low temperature of the capric acid (with its effect visible in the data in Figure 4, 5 and 6) is due to the flocculation/solubilization (as monomers, or assembled into small 505 vesicles/micelles) rather than to a gel-fluid membrane transition. The coexistence observed in Figure 6 (right) indicates that the decanol has the effect of partially preventing flocculation, so that a MLV phase is still present, with the amphiphiles in the gel phase so to give a thicker membrane (lowest temperatures in Figure 8 left). Upon chain melting at $\mathrm{T} \geq 10{ }^{\circ} \mathrm{C}$, the d-spacing decreases slightly ( $\leq$ $0.5 \mathrm{~nm}$ ), due to a decrease of the bilayer thickness when crossing the gel-fluid transition, as also

510 observed by ${ }^{17}$. From $\mathrm{T}=30^{\circ} \mathrm{C}$, the solvent induced swelling becomes more important and d-spacing starts to increase.

Most importantly in this study, the mixture containing decanol undergoes a high temperature phase transition, not observed in the pure FA system, which leads to much bigger (Figure 4), orientable (Figure 5), yet still bilayer (Figure 9) structures. High temperatures also have the effect of causing an 515 unbinding transition of the MLV swollen phase $\left(\mathrm{T} \approx 65-70{ }^{\circ} \mathrm{C}\right)$ that leads to unilamellar membranes (Figure 6 and 9), only observed in the case of the C10 mix. 
The peculiar oriented-like spectral shapes observed with NMR at $80{ }^{\circ} \mathrm{C}$ and $50{ }^{\circ} \mathrm{C}$ (Figure 5) have already been observed for bilayer-micelles (bicelles) when the system is under the form of small lipidic discs that align as a nematic phase in the magnetic field ${ }^{39-41}$. It has been also observed for 520 model and natural membranes (MLVs) that are deformed by magnetic fields ${ }^{42,43}$. This happens when the elastic energy maintaining the vesicles with an average spherical shape is lower than the magnetic energy ${ }^{43}$. In such a situation the vesicle is deformed as a prolate ellipsoid along the magnetic field direction, the elastic modulus of the membrane being orders of magnitude lower than that of classical plasma membranes, which are not affected by magnetic fields. Because vesicles are being detected

525 with neutrons we favour the latter explanation. As pointed out by the work of ${ }^{43}$, the extent of the huge deformation observed here (long-axis : short-axis ratio $\approx 8-10$, see Supp. Info) is directly proportional to the vesicle size. Therefore the observed high temperature transition that leads to bigger structures has likely favoured the occurrence of such deformation. Nevertheless, the membrane packing of the C10 mix vesicles is also stable at the highest measured temperature (Figure 4S, Supp. Info).

530 Taken together, these results point towards the appearance of large, unilamellar vesicles at $\mathrm{T} \geq 60{ }^{\circ} \mathrm{C}$ formed by fusion of the vesicles existing at low temperature. This interpretation is supported by the observed vesicle mean size increase (Figure 4), the MLV unbinding to give unilamellar vesicles (Figure 6, right) and the decrease of the small $(<100 \mathrm{~nm})$ vesicle fraction until complete disappearance (Figure 5, right and Figure 5S, Supp. Info). The second high-temperature broad 535 transition observed in the DSC thermogram of C10 mix (Figure 4) is therefore a result of such fusion process, rather than a shift of the equilibrium between vesicles and micelles as previously reported ${ }^{18}$.

We note that the occurrence of this high temperature conformational transition has probably been observed with its effect in previous studies, although not directly identified:

(i) Jordan and coworkers ${ }^{14}$, by studying a different system made with mixtures of $\mathrm{C} 10-\mathrm{C} 15$

$540 \mathrm{FA} /$ alcohols at strongly alkaline $\mathrm{pH}$, high salt concentrations $\left(\mathrm{NaCl}, \mathrm{MgCl}_{2}, \mathrm{CaCl}_{2}\right)$ and high temperature $\mathrm{T}=70{ }^{\circ} \mathrm{C}$ with confocal microscopy, observed in several cases the occurrence of big elongated structures, where "the filaments appeared to be composed of chains of individual vesicles". Although on different systems and in non-equilibrium conditions (the sample stage was not heated during measurements), their observation could be the effect of the high temperature transition described here. Although we observed oriented structures with ssNMR at high temperature, which could be because of an elongated shape of the bilayer structures, we could not conclude whether the orientation or also the deformation itself were triggered by the static magnetic field of the spectrometer. For this reason we refer to the high temperature products as large unilamellar vesicles, with a not necessarily spherical mean shape that is not the focus of the present study.

550 (ii) Mansy and Szostak ${ }^{16}$ examined a mixture of capric acid : decanol in 2:1 ratio by measuring the vesicle capability to retain encapsulated oligonucleotides as a function of temperature. They observed 
the occurrence of material leakage above $50-60{ }^{\circ} \mathrm{C}$. In view of our results, we can argue that the observed leakage may not be due simply to a sudden increase in the protomembrane permeability, but a consequence of the morphological changes happening above that temperature threshold: the conformational transition and, perhaps more importantly in this case, the unbinding transition of the bilamellar vesicle fraction (probably present as the experimental buffer $/ \mathrm{pH} /$ extrusion size conditions were the same as in our study). From this perspective, the actual permeability of the model protomembrane may still be sufficiently low even at higher temperatures, thus additional studies are required to address this point taking into account the MLV unbinding transition and the vesicle fusion processes that we identified.

The occurrence of this transition at $\mathrm{T} \geq 60{ }^{\circ} \mathrm{C}$ could appear as unfavourable in terms of the $\mathrm{C} 10 \mathrm{mix}$ stability at the highest temperatures, the focus of our study given the implications for the origin of life. The pure FA vesicles, although less stable at room temperature, would not undergo the high $\mathrm{T}$ transition and hence appear more thermostable after all. Nevertheless, our results (Figure 7) show that the temperature increase induces a partial vesicle disassembling in the pure capric acid that leads to a higher amount of micelles. Conversely, in the $\mathrm{C} 10 \mathrm{mix}$, no vesicle-to-micelle transition is observed, and the bilayer structuring (probed by SANS) and packing (probed by NMR) are preserved at the highest temperatures. Therefore, rather than protomembrane disruption, solubilization or micellar aggregation, the high temperature triggers the fusion of the small vesicles assembling in favour of large unilamellar bilayered structures.

\section{Conclusion}

In summary, we found that the addition of same-length fatty alcohol to a short chain C10 FA suspension in equimolar ratio leads to several substantial effects. It improves the vesicles' stability at room temperature at the expense of the other amphiphile states (micelles, monomers). It partially

575 prevents the vesicles from undergoing flocculation at temperatures lower than the expected FA Krafft point. Most importantly, it triggers a high temperature conformational change at $\mathrm{T} \geq 60{ }^{\circ} \mathrm{C}$ that leads to vesicle fusion with stable membranes at temperature as high as $80^{\circ} \mathrm{C}$, the highest measured in this study. On one hand, this sets a warning on the interpretation of the results from all experiments of this kind (i.e. whether what is observed correlates with the occurrence of such phase transition at high

580 temperature). In addition, as a perspective, it sets the basis for further studies: namely, whether such transition could serve as a prebiotic mean of solute exchange between different vesicles, as this would set a milestone in our understanding of origin of life related processes.

\section{Acknowledgements}

This work was funded by the French National Research Agency programme ANR 17-CE11-0012-01 to PO and JP. We benefited from the facilities and expertise of the Biophysical and Structural 
Chemistry platform (BPCS) at "Institut Européen de Chimie et Biologie" (IECB), CNRS UMS3033, Inserm US001, Bordeaux University http://www.iecb.ubordeaux.fr/index.php/fr/plateformestechnologiques. LM is supported by a scholarship from the Institut Laue - Langevin (ILL) PhD program. The authors thank ILL for neutron 590 beamtime on D33 (DOI: 10.5291/ILL-DATA.9-13-788) and D16 (DOI: 10.5291/ILL-DATA.TEST3108). The ILL Partnership for Soft Condensed Matter (PSCM) is acknowledged for the access to the DSC and DLS platforms, and for lab infrastructures. This work benefited from SasView software, originally developed by the DANSE project under NSF award DMR-0520547 [http://www.sasview.org/]. LM is grateful to Jean Paul Douliez and Sylvain Prevost for fruitful 595 discussions and Erick Dufourc for the valuable feedbacks.

This article is dedicated to our late colleague Isabelle Grillo

Supporting Information. Equations for the SANS model form factors; preliminary sample screening data; full list of parameters used for fits/simulation and annexes.

\section{References}

600 (1) Joyce, G. F.; Szostak, J. W. Protocells and RNA Self-Replication. Cold Spring Harb. Perspect. Biol. 2018, 10 (9), a034801.

(2) Segré, D.; Ben-Eli, D.; Deamer, D. W.; Lancet, D. The Lipid World. Orig. Life Evol. Biosph. 2001, 31 (1-2), 119-145.

(3) Fiore, M.; Strazewski, P. Prebiotic Lipidic Amphiphiles and Condensing Agents on the Early 605 Earth. Life (Basel, Switzerland) 2016, 6 (2), 17. https://doi.org/10.3390/life6020017.

(4) McCollom, T. M.; Ritter, G.; Simoneit, B. R. T. Lipid Synthesis under Hydrothermal Conditions by Fischer-Tropsch-Type Reactions. Orig. Life Evol. Biosph. 1999, 29 (2), $153-$ 166.

(5) Monnard, P.-A.; Deamer, D. W. Preparation of Vesicles from Nonphospholipid Amphiphiles. In Methods in enzymology; Elsevier, 2003; Vol. 372, pp 133-151.

(6) Budin, I.; Prywes, N.; Zhang, N.; Szostak, J. W. Chain-Length Heterogeneity Allows for the Assembly of Fatty Acid Vesicles in Dilute Solutions. Biophys. J. 2014, 107 (7), 1582-1590.

(7) Apel, C. L.; Deamer, D. W.; Mautner, M. N. Self-Assembled Vesicles of Monocarboxylic Acids and Alcohols: Conditions for Stability and for the Encapsulation of Biopolymers. Biochim. Biophys. Acta (BBA)-Biomembranes 2002, 1559 (1), 1-9.

(8) Morigaki, K.; Walde, P. Fatty Acid Vesicles. Curr. Opin. Colloid Interface Sci. 2007, 12 (2), $75-80$. 
(9) Hargreaves, W. R.; Deamer, D. W. Liposomes from Ionic, Single-Chain Amphiphiles. Biochemistry 1978, 17 (18), 3759-3768.

620 (10) Haines, T. H. Anionic Lipid Headgroups as a Proton-Conducting Pathway along the Surface of Membranes: A Hypothesis. Proc. Natl. Acad. Sci. 1983, 80 (1), 160-164.

(11) Maurer, S. E.; Tølbøl Sørensen, K.; Iqbal, Z.; Nicholas, J.; Quirion, K.; Gioia, M.; Monnard, P.-A.; Hanczyc, M. M. Vesicle Self-Assembly of Monoalkyl Amphiphiles under the Effects of High Ionic Strength, Extreme PH, and High Temperature Environments. Langmuir 2018, 34 (50), 15560-15568.

(12) Deamer, D. The Role of Lipid Membranes in Life's Origin. Life 2017, 7 (1), 5.

(13) Chen, I. A.; Salehi-Ashtiani, K.; Szostak, J. W. RNA Catalysis in Model Protocell Vesicles. J. Am. Chem. Soc. 2005, 127 (38), 13213-13219.

(14) Jordan, S. F.; Rammu, H.; Zheludev, I. N.; Hartley, A. M.; Marechal, A.; Lane, N. Promotion of Protocell Self-Assembly from Mixed Amphiphiles at the Origin of Life. Nat. Ecol. Evol. 2019, 3 (12), 1705-1714.

(15) Cornell, C. E.; Black, R. A.; Xue, M.; Litz, H. E.; Ramsay, A.; Gordon, M.; Mileant, A.; Cohen, Z. R.; Williams, J. A.; Lee, K. K. Prebiotic Amino Acids Bind to and Stabilize Prebiotic Fatty Acid Membranes. Proc. Natl. Acad. Sci. 2019, 116 (35), 17239-17244.

635 (16) Mansy, S. S.; Szostak, J. W. Thermostability of Model Protocell Membranes. Proc. Natl. Acad. Sci. 2008, 105 (36), 13351-13355.

(17) Douliez, J.-P.; Houssou, B. H.; Fameau, A.-L.; Navailles, L.; Nallet, F.; Grélard, A.; Dufourc, E. J.; Gaillard, C. Self-Assembly of Bilayer Vesicles Made of Saturated Long Chain Fatty Acids. Langmuir 2016, 32 (2), 401-410.

640 (18) Kapoor, S.; Berghaus, M.; Suladze, S.; Prumbaum, D.; Grobelny, S.; Degen, P.; Raunser, S.; Winter, R. Prebiotic Cell Membranes That Survive Extreme Environmental Pressure Conditions. Angew. Chemie 2014, 126 (32), 8537-8541.

(19) Guinier, A.; Fournet, G.; Yudowitch, K. L. Small-Angle Scattering of X-Rays. 1955.

(20) Frisken, B. J. Revisiting the Method of Cumulants for the Analysis of Dynamic LightScattering Data. Appl. Opt. 2001, 40 (24), 4087-4091. https://doi.org/10.1364/AO.40.004087.

(21) Davis, J. H.; Jeffrey, K. R.; Bloom, M.; Valic, M. I.; Higgs, T. P. Quadrupolar Echo Deuteron Magnetic Resonance Spectroscopy in Ordered Hydrocarbon Chains. Chem. Phys. Lett. 1976, 42 (2), 390-394. https://doi.org/https://doi.org/10.1016/0009-2614(76)80392-2. 
(22) Dewhurst, C. D.; Grillo, I.; Honecker, D.; Bonnaud, M.; Jacques, M.; Amrouni, C.; PerilloMarcone, A.; Manzin, G.; Cubitt, R. The Small-Angle Neutron Scattering Instrument D33 at the Institut Laue-Langevin. J. Appl. Crystallogr. 2016, 49 (1), 1-14. https://doi.org/10.1107/S1600576715021792.

(23) Hanczyc, M. M.; Fujikawa, S. M.; Szostak, J. W. Experimental Models of Primitive Cellular Compartments: Encapsulation, Growth, and Division. Science (80-. ). 2003, 302 (5645), 618 655 622.

(24) Chen, I. A.; Szostak, J. W. A Kinetic Study of the Growth of Fatty Acid Vesicles. Biophys. J. 2004, 87 (2), 988-998.

(25) Cape, J. L.; Monnard, P.-A.; Boncella, J. M. Prebiotically Relevant Mixed Fatty Acid Vesicles Support Anionic Solute Encapsulation and Photochemically Catalyzed Trans-Membrane Charge Transport. Chem. Sci. 2011, 2 (4), 661-671.

(26) Janiak, M. J.; Small, D. M.; Shipley, G. G. Nature of the Thermal Pretransition of Synthetic Phospholipids: Dimyristoyl-and Dipalmitoyllecithin. Biochemistry 1976, 15 (21), 4575-4580.

(27) Nagle, J. F.; Tristram-Nagle, S. Structure of Lipid Bilayers. Biochim. Biophys. Acta (BBA)Reviews Biomembr. 2000, 1469 (3), 159-195.

(28) Pabst, G.; Rappolt, M.; Amenitsch, H.; Laggner, P. Structural Information from Multilamellar Liposomes at Full Hydration: Full q-Range Fitting with High Quality x-Ray Data. Phys. Rev. E 2000, 62 (3), 4000.

(29) Demé, B.; Dubois, M.; Gulik-Krzywicki, T.; Zemb, T. Giant Collective Fluctuations of Charged Membranes at the Lamellar-to-Vesicle Unbinding Transition. 1. Characterization of a New Lipid Morphology by SANS, SAXS, and Electron Microscopy. Langmuir 2002, 18 (4), 997-1004.

(30) Seelig, J. Deuterium Magnetic Resonance: Theory and Application to Lipid Membranes. $Q$. Rev. Biophys. 1977, 10 (3), 353-418.

(31) Davis, J. H. The Description of Membrane Lipid Conformation, Order and Dynamics by 2HNMR. Biochim. Biophys. Acta (BBA)-Reviews Biomembr. 1983, 737 (1), 117-171.

(32) Dufourc, E. J.; Mayer, C.; Stohrer, J.; Althoff, G.; Kothe, G. Dynamics of Phosphate Head Groups in Biomembranes. Comprehensive Analysis Using Phosphorus-31 Nuclear Magnetic Resonance Lineshape and Relaxation Time Measurements. Biophys. J. 1992, 61 (1), 42-57.

(33) Douliez, J. P.; Bellocq, A. M.; Dufourc, E. J. Effect of Vesicle Size, Polydispersity and 680 Multilayering on Solid State 31P-and 2H-NMR Spectra. J. Chim. Phys. 1994, 91, 874-880. 
(34) Nallet, F.; Laversanne, R.; Roux, D. Modelling X-Ray or Neutron Scattering Spectra of Lyotropic Lamellar Phases: Interplay between Form and Structure Factors. J. Phys. II 1993, 3 (4), 487-502.

(35) Tyler, A. I. I.; Law, R. V.; Seddon, J. M. Methods in Membrane Lipids; Owen, D. M., Ed.; 685 Springer, 2015.

(36) Pedersen, J. S. Analysis of Small-Angle Scattering Data from Colloids and Polymer Solutions: Modeling and Least-Squares Fitting. Adv. Colloid Interface Sci. 1997, 70 (0), 171-210.

(37) Mutz, M.; Helfrich, W. Unbinding Transition of a Biological Model Membrane. Phys. Rev. Lett. 1989, 62 (24), 2881.

690 (38) Israelachvili, J. N.; Mitchell, D. J.; Ninham, B. W. Theory of Self-Assembly of Hydrocarbon Amphiphiles into Micelles and Bilayers. J. Chem. Soc. Faraday Trans. 2 Mol. Chem. Phys. 1976, 72, 1525-1568.

(39) Raffard, G.; Steinbruckner, S.; Arnold, A.; Davis, J. H.; Dufourc, E. J. TemperatureComposition Diagram of Dimyristoylphosphatidylcholine- Dicaproylphosphatidylcholine "Bicelles" Self-Orienting in the Magnetic Field. A Solid State 2H and 31P NMR Study. Langmuir 2000, 16 (20), 7655-7662.

(40) Aussenac, F.; Laguerre, M.; Schmitter, J.-M.; Dufourc, E. J. Detailed Structure and Dynamics of Bicelle Phospholipids Using Selectively Deuterated and Perdeuterated Labels. 2H NMR and Molecular Mechanics Study. Langmuir 2003, 19 (25), 10468-10479.

(41) Loudet-Courreges, C.; Nallet, F.; Dufourc, E. J.; Oda, R. Unprecedented Observation of DaysLong Remnant Orientation of Phospholipid Bicelles: A Small-Angle X-Ray Scattering and Theoretical Study. Langmuir 2011, 27 (15), 9122-9130. https://doi.org/10.1021/la1050817.

(42) Pott, T.; Dufourc, E. J. Action of Melittin on the DPPC-Cholesterol Liquid-Ordered Phase: A Solid State 2H-and 31P-NMR Study. Biophys. J. 1995, 68 (3), 965-977. https://doi.org/10.1016/S0006-3495(95)80272-9.

(43) Dazzoni, R.; Grélard, A.; Morvan, E.; Bouter, A.; Applebee, C. J.; Loquet, A.; Larijani, B.; Dufourc, E. J. The Unprecedented Membrane Deformation of the Human Nuclear Envelope, in a Magnetic Field, Indicates Formation of Nuclear Membrane Invaginations. Sci. Rep. 2020, 10 (1), 5147. https://doi.org/10.1038/s41598-020-61746-0. 

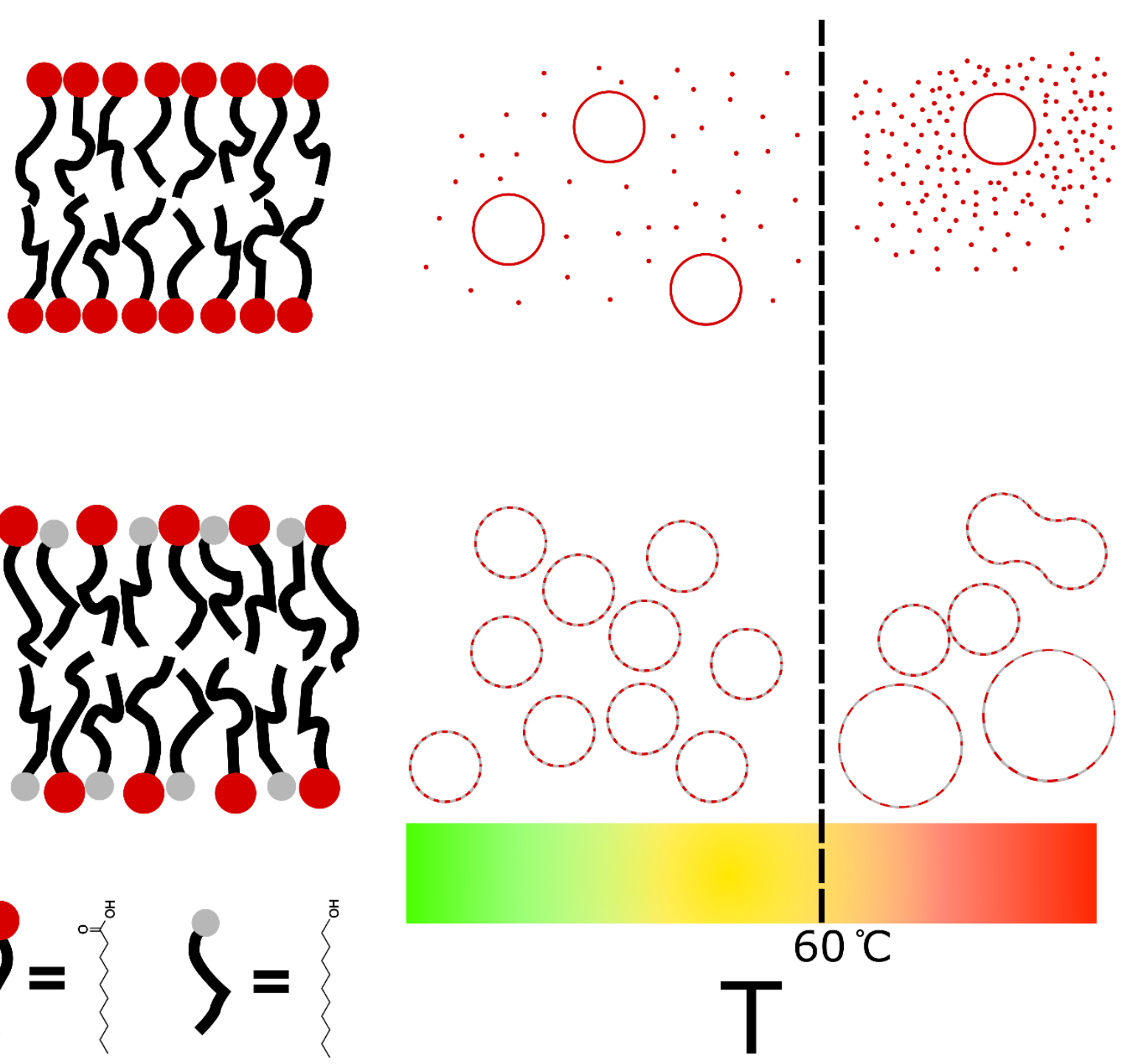